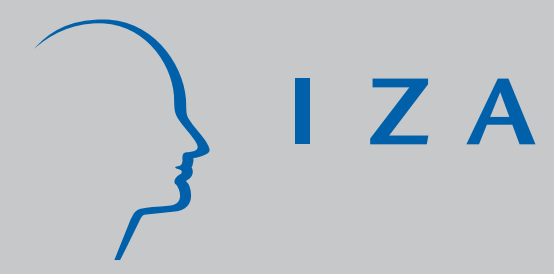

IZA DP No. 3370

The Stability of Mixed Income Neighborhoods in America

Douglas J Krupka

February 2008 


\title{
The Stability of Mixed Income Neighborhoods in America
}

\author{
Douglas J. Krupka
}

IZA

\author{
Discussion Paper No. 3370 \\ February 2008
}

\author{
IZA \\ P.O. Box 7240 \\ 53072 Bonn \\ Germany \\ Phone: +49-228-3894-0 \\ Fax: +49-228-3894-180 \\ E-mail: iza@iza.org
}

\begin{abstract}
Any opinions expressed here are those of the author(s) and not those of IZA. Research published in this series may include views on policy, but the institute itself takes no institutional policy positions.

The Institute for the Study of Labor (IZA) in Bonn is a local and virtual international research center and a place of communication between science, politics and business. IZA is an independent nonprofit organization supported by Deutsche Post World Net. The center is associated with the University of Bonn and offers a stimulating research environment through its international network, workshops and conferences, data service, project support, research visits and doctoral program. IZA engages in (i) original and internationally competitive research in all fields of labor economics, (ii) development of policy concepts, and (iii) dissemination of research results and concepts to the interested public.
\end{abstract}

IZA Discussion Papers often represent preliminary work and are circulated to encourage discussion. Citation of such a paper should account for its provisional character. A revised version may be available directly from the author. 


\begin{abstract}

\section{The Stability of Mixed Income Neighborhoods in America*}

Whether people of differing types can live happily together is one of the most important social and political questions concerning urban areas. From a variety of theoretical perspectives, such mixing seems extremely unlikely. While the theoretical result seems well supported in the context of race, the evidence for income mixing is much less stark. Compared to the strict segregation predicted by the models (and embodied in the context of race), Americans live in economically diverse neighborhoods. While this has lead to some further theoretical experiments, the stability of this mixing has never been addressed as an empirical matter. It would be naïve to look at cross-sectional snapshots of income mixing as representing stable situations, since neighborhood change is a prevalent feature of American urban economies. This paper sketches out the empirical implications of slow transition towards the predicted equilibrium, and tests those implications. It is the first paper to directly evaluate the persistence and stability of mixed-income communities. The results are supportive of the three models of income segregation: income mixing appears to be unstable, although the adjustment process is slow. This work is of especial importance due to the focus mixedincome communities receive in the urban planning and policy.
\end{abstract}

JEL Classification: R14, R2, R11, R31, N9, O2

Keywords: mixed-income, urban policy, neighborhood dynamics, neighborhood change, sorting, segregation

Corresponding author:

Douglas J. Krupka

IZA

P.O. Box 7240

D-53072 Bonn

Germany

E-mail: dkrupka@iza.org

\footnotetext{
* This document contains demographic data from GeoLytics, E. Brunswick, NJ. The author would like to thank Geoffrey Turnbull, Doug Noonan, Thomas Davidoff, Joseph Smith, Marco Castillo, David Jaeger and participants of the Workshop on Public Finance and Economic Policy at the University of Chicago for many helpful comments and Guevero Yao for research assistance. All errors are my own.
} 
This paper aims to assess the long-term stability of mixed-income neighborhoods. ${ }^{1}$ Are people willing to live with others of different socio-economic status, or are situations in which highly integrated neighborhoods exists inherently unstable, with rich or poor residents fleeing the neighborhood? This is an important question because mixed income neighborhoods have been hypothesized to have a wide variety of beneficial properties, such as helping their low-income residents improve their economic and social standing.

The early theoretical work on the subject was unequivocal: mixed-income neighborhoods did not represent stable equilibria. This theoretical result was extremely robust. The work of Tiebout (1956), Alonso (1964) and Schelling (1969, 1971) all point towards this result, from extremely different sets of assumptions about people's behavior.

These results, however, seemed in stark contrast to the empirical reality. American cities, while highly racially segregated, are well mixed economically (Duncan and Duncan 1955). In most cities, well over half the variance in income came from variations within the neighborhood, as opposed to variation across neighborhoods (Farley 1977). ${ }^{2}$ This apparent failure of the three fundamental models to predict a major aspect of American urban life brought forth a series of papers trying to extend the models to allow for stable income mixing. ${ }^{3}$

All these articles, however, have missed a central observation: every estimate of the extent of income mixing has been based on cross-sectional data. That is, estimates of income segregation have almost without exception relied on data from one census.

\footnotetext{
${ }^{1}$ The language of the paper is that of static models, so "stability" is used to mean a state in which there is no tendency for change. In a dynamic model, transitional dynamics can be stable, even as they move to a long-run steady state. A dynamic interpretation of this paper's question is: can mixed-income neighborhoods exist in the long run, or are they only the products of transitional dynamics moving from one segregated steady state to another?

${ }^{2}$ Massey and Eggers (1990) and Miller and Quigley (1990) are two more recent papers in the same vein.

${ }^{3}$ Miyao (1978), de Bartolome (1990), Frankel (1998) and de Bartolome and Ross (2003) are some examples reviewed below.
} 
Studies using several years make comparisons at the national (or metropolitan) level, but never look at individual neighborhoods.

This oversight is important for two reasons. First, mixed income neighborhoods are a goal of federal and local urban policy. Understanding the stability of such neighborhoods can thus inform implementation and prioritization of these policies. Secondly, looking only at cross-sectional data leaves the processes at work behind the snapshot unobserved. The theoretical models describe equilibria: situations in which there is no process at work which will change the basic situation. In this case, the models predict what cities will look like once they have stopped changing. Thus, cross-sectional data cannot assess the accuracy of these predictions unless we could believe that American cities had reached some long-run equilibrium.

In the presence of widespread urban transformations, with metropolitan areas like Atlanta doubling in population over the past decades while Detroit's central city population declined by half, it seems unlikely that the American Metropolitan System has reached its long-run equilibrium. ${ }^{4}$ Given endemic urban change, we are left with no real understanding of whether mixed-income neighborhoods can remain integrated, or if income mixing is largely a product of shifting urban demographics.

This paper uses panel data of American census block groups to address this fundamental question. Comparing the economic status of neighborhoods across time, it is the first paper ever to directly test the predictions the three seminal papers make about income sorting. With data on a income spread within each neighborhood and a number of other neighborhood level variables collected over time, I am able to assess whether

\footnotetext{
${ }^{4}$ Rosenthal (2008) documents the long-run changes that most urban neighborhoods exhibit.
} 
more economically mixed neighborhoods can maintain their high level of mixing, or whether this mixing will be fleeting.

The rest of the paper is organized as follows: Section I describes the assumptions and results on income sorting of the three fundamental papers by Tiebout, Alonso and Schelling. It then outlines the contributions of later authors trying to make sense of the seeming inconsistency between theory and reality. Section II informally sketches the implications of the models in a dynamic setting with gradual adjustment toward equilibrium. Section III puts forward a slightly more formal model, which derives some empirical regularities that should pertain if income mixing is not stable. Section IV lays out the empirical strategy. Section V describes the data, which are derived from U.S. Census data normalized to 2000 boundaries. This allows us to take the census block group (“neighborhood”) as a unit of analysis instead of the metropolitan area as a whole. Section VI presents the results, which are supportive of the contention that income mixing is to a large extent an artifact of disequilibrium behavior. A seventh section checks the robustness of these results to changes in specification, and examines some side results of the formal model in Section III. Finally, section VIII concludes and remarks on the significance of this research for federal, state and local urban policy.

\section{Literature Review.}

The three fundamental contributions to this literature are briefly sketched below. Some extensions to these models are then considered briefly. Finally, the empirical implications of this literature are discussed.

Reinterpreting suburbs as clubs in which like-minded people lived together using local politics to ensure preferred levels of public spending (on things like education, 
public safety, etc.), Tiebout showed in 1956 that people would choose residences according to their desires for such spending. This process of "voting with your feet" would lead to a multitude of homogenous suburbs, with people of similar income living together, and working hard to keep people of lower economic status from moving in. The model seemed to capture something essential about the suburbanization process that was picking up steam during that decade.

Alonso (1964) developed the “canonical” model of urban economics. He posited a city with one employment center (downtown). People traded off between short commutes near the center and cheaper land further out. In the absence of any jurisdictional differences in public spending, this model produced a city which, in equilibrium, was characterized by circular zones around the downtown area, each containing only one income class. As usually interpreted, the model implied concentrated poverty in the inner zones surrounded by successively wealthier zones of residence. ${ }^{5}$ Just as in the model presented by Tiebout, this model predicted near-perfect segregation by income.

Finally, Thomas Schelling (1969) came to the same conclusion from a completely different direction. Assuming people cared about who their neighbors were, he generated a model in which people moved in or out of neighborhoods until the city was again perfectly segregated. This occurred even under fairly unobjectionable assumptions about people’s preferences (e.g. they don’t want to be in the minority in their neighborhood). Although the model is usually interpreted in terms of racial segregation, the results are easily extended to income.

\footnotetext{
${ }^{5}$ Brueckner and Rosenthal (2005) offer a compelling alternative to the standard interpretation of this result.
} 
It is important to stress the fundamental nature of the above contributions. Tiebout's casting of local jurisdictions as public-spending clubs has been the central lens through which local public finance issues are viewed by economists. The underpinnings of the Alonso's monocentric city model have been the linchpin of urban economics. Schelling’s application of simple preferences in complex residence decisions has helped us understand the intractability of racial segregation. While all these models have been elaborated in the ensuing decades, their fundamental significance and insightfulness have never been seriously doubted, nor should they be.

As mentioned in the introduction, the stark predictions of total income sorting do not seem to be borne out by real city neighborhoods. Realizing the dissonance between reality and the theoretical predictions, economic theorists have offered refinements to the basic models that they feel can help explain the apparently high levels of income mixing in American cities. Most of these refinements come down to assuming some sort of advantage to living near people of divergent incomes. These advantages are derived in many ways, and sometimes these additional assumptions are able to induce mixedincome neighborhoods (sometimes, however, they are not).

Miyao (1978) examines the possibility of a mixed-income city in the presence of negative inter-group externalities (preference for segregation). His "city" is completely open and non-spatial, and thus is more similar to a neighborhood than a metropolitan area, where access to the CBD varies over space. In the non-spatial case, mixing is not stable. Miyao is able to generate a stable mixing equilibrium by introducing distance to the CBD into the model, but only at the city level: the city has both rich and poor 
residents, but within the city residents are arranged in concentric rings alla Alonso and Muth. This mixing equilibrium thus does not predict mixing at the neighborhood level. de Bartolome (1990) allows for asymmetric inter-group externalities in a jurisdictional set-up where poor people like to live with rich people, but rich people want to avoid the poor. In this model, there are multiple equilibria, of which income mixing is one. The model is mute on the spatial distribution of income classes within a jurisdiction. Frankel (1998) derives an asymmetric positive inter-group externality by assuming that the presence of poor people lowers the price rich people have to pay for private goods and services. In this environment, income mixing is one of multiple equilibria, even in the presence of rich people's preference not to associate with poor people. The model assumes, however, that rich people and poor people buy the same sorts of goods and services, which is an undesirable assumption due to the non-zero income elasticities of many goods and services. Thus, Frankel (1998) may be a better model of transitoryincome mixing within groups with similar permanent income.

Finally, de Bartolome and Ross (2003) use a model with jurisdictional public service provision and Alonso-style access considerations to model residential choice within an urban area. For certain parameters of their model, they show that both jurisdictional and spatial mixing are possible. However the range of the parameter values where this is possible is small compared to the total parameter space, and in some parameter value combinations, mixing only occurs across jurisdictions, not within jurisdictions.

Indeed, it is not difficult to imagine other models using distinctions between permanent and current income, taste heterogeneity or some other means to induce 
equilibrium income mixing. However, the general take away of this literature is that with enough massaging a model can be generated that will allow for mixing, sometimes, but that the qualitative theoretical results of Schelling, Alonso and Tiebout are remarkably robust. In the face of the evidence that income mixing is fairly common (at least compared to racial segregation), the theoretical literature has not been able to reconcile these fundamental theories with the evidence. On the one hand, this can be taken as a deficiency in the theoretical literature. On the other hand, it might suggest that the evidence on income mixing needs a second look.

Such a second look is extremely important due to the fundamental deficiency in the evidence against sorting up to this point: every one of the current estimates of the extent of income mixing relies on either cross-sectional data or takes very large aggregates (such as the metropolitan area) as their unit of analysis as in Jargowski (1996, 2003). Neighborhood level trends in income mixing have gone largely unexplored. Very few authors have looked at what happens to the individual neighborhood over time. ${ }^{6}$ If the equilibria suggested in the three fundamental models are not reached instantaneously, these studies simply cannot speak to the accuracy of the models’ predictions.

\section{Informal Theory.}

This section takes each of the three fundamental papers and sketches out dynamic versions of them. By allowing for non-instantaneous transitions, it shows that in all three of the modeling “worlds” assumed by these authors, the sorting equilibrium will likely be

\footnotetext{
${ }^{6}$ Two exceptions are Aaronson (2001) and Helms (2003), whose results are tangentially supportive of the work presented here. Because neither of these authors is examining income mixing per se, their results are only suggestive in terms of the question of neighborhood stability. Some dynamic evidence in support of long-run integration in the racial context is available in Clapp and Ross (2004).
} 
reached via periods of unstable transitions characterized by some degree of income mixing. The contention of this paper is that cross-sectional evaluations of income-mixing have been contaminated by assuming that the mixing evident in the data represents an equilibrium situation, but do not account for the fact that income mixing may be largely due to disequilibrium transitions.

\section{A) Alonso and the classical mono-centric city.}

In 1964, William Alonso proposed a theory of a monocentric city in which people faced a trade-off between access to the employment center and cheaper rents. Muth (1969) expanded on this model. Close-in residences cost more, but offered savings in terms of travel time to and from work each day. Because the opportunity cost of time varies with income, and because the demand for land is also assumed to have a non-zero income elasticity, this basic set-up has stark predictions about income mixing: it will not occur. There are two possible cases.

The first case is that income increases demand for land faster than it increases commuting costs. If this is the case, a monocentric city will be characterized by concentric rings of homogenous residents, with people becoming richer as one goes further from the center. The second case is nicer for central city mayors, but no better for fans of mixed-income neighborhoods. If commuting costs increase faster with income than demand for land, the equilibrium is exactly reversed. People still sort themselves into concentric rings of identical incomes, but now the rich people live "downtown.” The model has been extended to allow for the existence of polycentric cities, non-monotonic income gradients and additional dimensions over which people vary; the central intuition 
that similar people want to live in similar places (that is, sort) holds up in all these reformulations.

While the Alonso model is static, the dynamics of the model can be understood through examination of its comparative statics. To sketch out how substantial amounts of income mixing are consistent with a slightly extended Alonso-type model, we present in figure 2.1 a situation in which there are three groups: poor Baptists, rich Catholics and Heathens. Heathens are like Catholics, except with fewer kids (which lowers their income elasticity of demand for land) and with two-wage-earner family structure (which increases their income elasticity of commuting costs).

Figure 2.1: Transitions in a mono-centric city
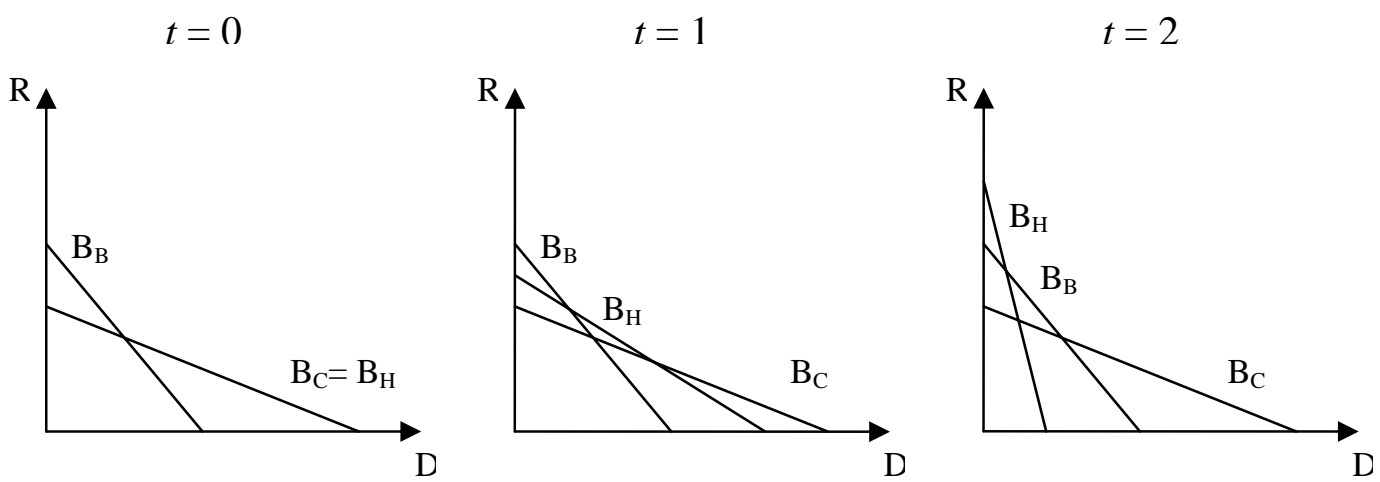

To motivate the changes in our city system, however, we assume that these Heathens arise suddenly out of the previous population of Catholics: the new generation of rich people are made up of low-fertility Heathens and traditional families with high fertility and stay-at-home moms. At $t=0$, Heathen incomes are such that they have the same bid-rent curve as rich Catholics, but both groups experience a steady increase in 
income over time. At time zero, Heathens and Catholics coexist peacefully in the outskirts of the city. As non-poor incomes increase, the Heathen bid-rent function becomes steeper than Catholics’ bid-rent function, and they cluster at the inside boundary of the non-poor areas as represented by the graph for $t=1$. $^{7}$ Finally, at $t=2$, the incomes of Heathens grow so high that they are actually able to out-bid Baptists for inner-city homes.

While the transition from $t=0$ to $t=1$ represents a somewhat continuous shift of Heathens concentrating closer into their previous range, the transition from period one to period two represents a leap-frog action of a high income group moving to a new homeland inside an existing group which then must move outward. In this situation, Baptists are now surrounded by rich neighborhoods on each side. This represents a major shift in urban structure, and it is the dynamics of this shift that are at issue.

The three time periods depicted in figure 2.1 represent equilibria. During the transition between periods one and two, the bid-rent function of the Heathens slowly becomes as steep as that of the Baptists, until - at some critical point in "continuous" time between $t=1$ and $t=2$ - Heathen bids in the central city start to be higher than Baptists' bids. It is the behavior at and around this moment that we need to consider.

A naïve interpretation of the model would imply that as soon as the bid-rent function of the Heathens is steeper than that of the Baptists, there is a cataclysmic shift in population, replete with caravans of heathens trucking in their Ikea furniture to their new condominiums as the poor Baptists trek down a trail of tears to their new slums in the

\footnotetext{
${ }^{7}$ Actually, they will occupy some areas in which only rich people lived and some in which poor people lived. As groups shift around the city, the bid-rent functions of the other groups will adjust upward or downward so that everyone has a place to live. These considerations are eschewed here to make the presentation simpler.
} 
inner-ring suburbs. State and local police guide and guard the counter-directional parades, and there is looting.

Of course, this is not how it happens. But it is important to stress that an analysis of cross-sectional data that assumes we are observing equilibrium outcomes is essentially making exactly this assumption: that neighborhood transitions happen quickly enough that we need not worry about them when we analyze census figures.

In reality, as the bid-rent function of Heathens overtakes that of Baptists, the difference is at first quite small. At first, even a poor renter paying on the actual bid-rent function would hardly notice the difference between his previous rent and the new market rent on the new Heathen bid-rent function.

Moreover, owners of homes, whose "rent" is only an opportunity cost, would have a hard time sensing this minute increase in their opportunity costs without considerable market research. Absentee landlords and management companies would similarly have a hard time, at first, realizing that they should be charging a new, Heathencompatible rent. Since rich Heathens are probably moving into different types of residences than poor people, it is likely that landlords will feel that the cost of refurbishment is not warranted by the tiny increase in rent they could charge to the new Heathen market, at least at first.

As Heathen incomes grow, however, their bid-rent function steepens, and the differences between the old, Baptist bid-rent function and the new, Heathen one will be easier to identify and harder to ignore. Landlords will start kicking out old tenants as their leases end and beginning the process of refurbishment. Apartments will convert to condominiums. Eventually the increase in property value will be too much even for 
crotchety owners to ignore. Their opportunity cost of residence will mount and they will eventually sell their residence. Eventually, all the old residents that are left are people with very high subjective costs of relocation and a few lazy landlords. These people eventually die off, and the inner city neighborhood will be fully gentrified.

To at least some extent, this dynamic story relies on deviations from strict rationality, and thus may not be fundamentally satisfying for some of us. This weakness is especially critical since no attempt is made here to fully draw out a structural theory of neighborhood transition, which might include upward sloping supply curves of contractors as an additional break on instantaneous gentrification. However, the intuitive model advanced above seems much closer to the truth about gentrification than the naïve rationalist approach outlined previously.

So, as time moves from period one to period two, we move from one equilibrium (the poor in the inner-city) to a new stable equilibrium (the poor sandwiched between Heathens and rich Catholics). The intervening time period could be quite extended. If it is much longer than 10 years, studies using census data at the metropolitan level will be guaranteed to be picking up large amounts of disequilibrium mixing in their estimates of neighborhood income segregation.

B) Schelling and preferences for neighborhood racial composition.

Thomas Schelling's 1969 paper about neighborhood sorting came at the question of neighborhood integration from a completely different direction. The main focus of his model was not income segregation, but racial segregation. He showed that, even given relatively unobjectionable preferences for neighborhood racial composition, 
neighborhoods would become perfectly segregated. The intuition of this model was later extended (Schelling 1971).

The intuition is quite simple: suppose that every white person liked black people, but just didn't want to stick out too much in their own neighborhood. Assume blacks feel similarly about whites. To operationalize this, we may say that no one wants to live in a neighborhood where over, say, $50 \%$ of their neighbors were the other race.

It is clear that in such a situation, given an all white neighborhood, no black would be willing to move in and - given an all black neighborhood - no white person would be willing to move in. An evenly mixed neighborhood (which in principle is acceptable to each race) has an inherent instability: if there is a sudden change in the population of blacks (e.g. because of relocation from the south), this could push the population of a neighborhood past the racial tipping point. If enough blacks move in that they make up a larger percentage of the population, all the whites will move out. Once this happens, no white will be willing to move into the neighborhood.

Schelling's analysis focused on racial preferences, but is easily extendable to preferences over economic status. For instance, people might like living in mixed income neighborhoods, but don't like feeling too poor. This assumption could be formalized by assuming that people do not want to be in the poorest $10^{\text {th }}$ of the neighborhood income distribution. ${ }^{8} \quad$ In this case, any neighborhood will eventually unravel: as the poorest leave, the distribution shifts, leaving a new group of people in the position of being "too poor" for the neighborhood. As succeeding groups of people leave, eventually all that is left is a group of people with exactly the same income. The city

\footnotetext{
${ }^{8}$ People may vary with their tolerance for being different in a number of ways. This example is merely illustrative. Such preferences could arise for a variety of very plausible reasons.
} 
becomes completely segregated, despite everyone's preference for living in mixedincome neighborhoods.

In this world, it is people's preferences for being surrounded by people not too unlike themselves that drives segregation. Focusing on the equilibrium condition, however, causes us to loose sight of the process by which such an equilibrium is reached. We could assume, stupidly, that people in these neighborhoods do annual analyses of their neighbors' tax records so that they can calculate their income percentile, and move immediately if the calculation comes out poorly. If people fold back the model, they will realize that any variation in income within the neighborhood (perhaps because someone got a raise) will instantaneously cause everyone in the neighborhood except the richest person to move away. ${ }^{9}$ The neighborhood would instantly be repopulated by people moving out of neighborhoods for which they are no longer rich enough.

This is clearly nonsense. It is, however, the implicit assumption we make if we interpret income mixing in our decennial census as representing a meaningful estimate of equilibrium economic integration.

More realistically, people notice the cars getting nicer, the shops and restaurants getting more expensive, the church services getting more boring, and eventually leave because there is something they don't like about "the way the neighborhood has gone." If people also dislike being around people much poorer than themselves, the logic works in the opposite way: slowly, people realize that the percent of domestic cars on the street is increasing, the shops sell only inferior goods and the crime rate and amount of litter is

\footnotetext{
${ }^{9}$ Or, if people do not wish to seem too poor or too rich, only the person with the income closest to the average or median income would want to stay.
} 
increasing. It becomes harder to get a good nap during church on Sundays. They leave, eventually, because they feel like the neighborhood "took a wrong turn” sometime back.

The intervening years could be quite long and tedious, as residents go to council meetings, form organizations to deal with the changes, or simply take a long time to realize what is happening. The Schelling model suggests they will eventually give up and leave, or force the intruding group out, ${ }^{10}$ but this equilibrium behavior occurs only in the long run. In the short run, there will be large amounts of mixing as the group of previous residents grapples with the reality of the intruding group. If it takes us more than, say, ten years to get from the short run to the long run, our estimates of income mixing from census counts are guaranteed to be contaminated by disequilibrium behavior.

C) Tiebout and public expenditure clubs.

Tiebout's model of public good provision was a brilliant simplification which brought out essential elements of the forces at work in urban areas. The basic idea is that if there are enough jurisdictions in a metro area, there are no external effects and commuting is not an issue, people will move to jurisdictions that provide their preferred level of public services, and these public services will be provided efficiently, as in a market for private goods. People will sort into jurisdictions according to their preferences for the provision of these locally provided public goods.

The analysis need not end there. Any other kind of amenity could be reinterpreted in a similar way, whether locally provided or exogenously determined. Although this sort of extension is usually made to the Alonso model of the mono-centric

\footnotetext{
${ }^{10}$ The history of Hyde Park, Illinois provides an example of how this can be done.
} 
city, ${ }^{11}$ I discuss it here because amenity sorting can be seen as a generalization of the Tiebout model, which focuses on one type of amenity: locally provided public goods. Amenities may be provided by a jurisdictional government according to some technology (low crime rates, clean streets) or exist independently of local government activity (location near a lake, or away from the tanneries). The central idea of Tiebout sorting and of the generalized amenity version of the Alonso model - is that people sort according to their preferences for various location-specific qualities, some of which are inherent to the location and some of which are decided through a complicated process of politics and intra-metropolitan residential migration.

If we make a further assumption that people's preference for such locationspecific characteristics is related to their income, the Tiebout model and the extended Alonso model both predict strong sorting by income. If willingness to pay for public expenditures or other amenities are correlated only to income, jurisdictions with different levels of the amenity or public service will attract different populations of residents, based on their incomes. Once equilibrium is reached, tax levels and land prices (not to mention zoning laws) will have adjusted to make it non-optimal for people of other income classes to move into the jurisdiction. ${ }^{12}$ Because of inter-jurisdictional competition, if there is a mixed income neighborhood, its residents will find it beneficial to move away in search of jurisdictions that are better-suited to their tastes/income.

Now, of course, tastes for amenities and public services are related to more than just income: poor people with large families may in principle be willing to pay as much

\footnotetext{
${ }^{11}$ See Diamond and Tolley (1982) for a rigorous version of the model in the context of the monocentric city.

${ }^{12}$ The real Tiebout model says much more than this brief synopsis. We avoid the aspects of his model which deal with the optimal response of city managers.
} 
for good schools as rich people with small families. In uni-dimensional amenity space, with few jurisdictions, this could lead to income mixing. However, in a world with many different amenities and many kinds of public spending, and in which residents of a metro area have choices between large numbers of jurisdictions (and near continuous choice over most amenities), it seems unlikely that much mixing will exist in the long run.

To demonstrate how mixing will be apparent in the short run even when it is unstable in the long run, we imagine a small, monocentric town with three jurisdictions (A, B, C) and 300 residents, 100 of whom begin the period rich, while the other 200 of them are poor. We begin the story with a stable situation in which Tiebout sorting has already taken place: all the rich residents live together in jurisdiction A, with high levels of public services, while the two hundred poor residents live in the other two jurisdictions (B, C). All three jurisdictions have the same access to the small down-town area, and the populations of the two poor jurisdictions are identical.

Now, imagine that a small factory or call center is opened in the CBD able to hire 100 low-skill laborers in high-wage manufacturing jobs. The poor people who are able to obtain one of these positions will become middle class, while the rest remain poor in their old jobs. Since there is no difference between the populations of the two poor jurisdictions, we can expect about fifty poor people from each jurisdiction to be hired, propelling them into the middle class. In the short term, we have two jurisdictions exhibiting substantial income mixing: middle-class workers are as likely to live with poor people as they are to live with their own kind.

What is the likely long-term effect of this change in the income distribution? The Tiebout model suggests that the new middle class laborers will want to have higher levels 
of public services than their poor neighbors, and will choose to move into one of the two poor jurisdictions (B), forcing the poor residents of B to move in with the poor residents left behind in C. These poor migrants will be grateful they did so, as they would not be willing to pay the high taxes the middle class residents of B will prefer.

The model does not specify the process of transition. It would be consistent with the model to assume that the mayors of the two jurisdictions get together and play rockpaper-scissors to decide who gets to keep the new middle class residents and who gets stuck with the poor people. The next day, or perhaps later that afternoon, fleets of moving trucks arrive at the resultant residences to truck the migrants' possessions into either the middle-class or poor jurisdiction, as the case may be. As ridiculous as this scenario sounds, it is essentially what we are assuming if we take cross-sectional neighborhood income distributions as representing stable, long-run equilibria.

A more realistic story entails a long process of newly middle class residents of each jurisdiction becoming dissatisfied with the public service provision in their jurisdiction. In the jurisdiction where they make up a bare majority (due to random chance, assume it is jurisdiction B) they are able to use political means to increase taxes and service levels, but this will take time. Poor residents of B may try to prevent these tax and service increases, and may mount efforts for tax relief on a periodic basis. It may be a long time - several election cycles - before they finally realize that the tax changes are effectively permanent and decide to relocate to jurisdiction C. In jurisdiction C, middle-class residents may try increasing taxes through political means several times before finally giving up and moving to B. By the time poor residents in B and middleclass residents in $\mathrm{C}$ realize that a move is both beneficial and inevitable, many years may 
have passed. Even at that point, the counter-directional migration may take several years as potential migrants wait for houses to come up for sale. A constraint on the resources available to undertake moves may also slow down the adjustment process, even after the lengthy period in which people realize the necessity of the move.

It is hard to say exactly how long it will take the short run, disequilibrium mixing evident in the above illustration to transition into the long-run, equilibrium sorting the model predicts. It could take several election cycles and even then may happen only gradually. However, it is important to stress that, if this transition period lasts any longer than about ten years, our assessments of income mixing from census data will be guaranteed to be contaminated by disequilibrium mixing.

D) Comments on these models.

The above sketches are extremely unsatisfactory because none offer fully workedout models of the system or dynamics they describe. They are offered to motivate the empirical section to follow, and to offer some intuitive support for three seminal articles in the face of empirical and theoretical challenges based on simplified, static interpretations of the models. By considering the dynamics of changing equilibria in the real world, it becomes evident that income mixing in neighborhoods is evidence against these models only if we believe the neighborhood has reached equilibrium.

One final remark seems in order about the difference between racial and economic segregation. Racial segregation is extremely high in America, and the Schelling model seems to capture some important stylized facts about the process of neighborhood change in racial composition. One reason why this might be is that equilibrium is reached faster in the case of racial segregation than in the case of economic 
segregation. This might be because it is almost impossible not to know the race of your neighbor. Thus, if people have racial preferences, they are easily acted upon. If race is used by people as a proxy for other things that mater more (e.g. criminality), then the accuracy of this proxy is not as important as the fact that it is extremely visible and easily verifiable. Once several black families move into a neighborhood, it is (and was) easy for uncomfortable white residents to "fold back" and figure out what is going to happen. Thus, equilibrium is reached quickly.

On the other hand, economic preferences (if they exist) are much harder to act upon because the economic status of a neighbor is harder to verify. Income is also an important correlate of many other important qualities, such as demand for public and private goods and services. The way in which income works is thus not directly, but through reasonably complicated market effects: through changing rent gradients, shifting retail mixes and a slow and poorly-understood public choice mechanism. Such changes will take far longer to be obvious to residents, be harder to verify and less readily folded back. This does not mean the concept of equilibrium is not valid in these situations, it just means that it will take longer to reach, and will be reached somewhat less consciously by its participants.

\section{A More Formal Model. ${ }^{13}$}

This section lays out a simple sketch of neighborhood change. The model is purely mechanical. Its purpose is to show that the instability of mixed income neighborhoods - as derived by Tiebout, Alonso and Schelling - has certain implications,

\footnotetext{
${ }^{13}$ This theoretical sketch concerns itself with deriving some additional results that are not the focus of the empirical section. Impatient readers may reasonably skip this section without serious loss of continuity.
} 
so that those implications can be used as a guide for the empirical section to follow. We assume a very simple income distribution: $i n c_{i}=\{0,1\} .^{14}$ A neighborhood's average income in time period $t$, is thus simply the proportion of the neighborhood's population that are in the higher income group: $x_{t} \in[0,1]$, and the neighborhood variance in income is $\sigma_{t}=x_{t}\left(1-x_{t}\right)$.

To represent the instability of mixed income neighborhoods, we assume that each neighborhood has an equilibrium use dictating that it be inhabited by only rich or poor people, and we assume that neighborhoods will move towards this equilibrium:

1) $x^{*}-x_{t}=\alpha\left(x^{*}-x_{t-1}\right)-e_{t}$,

where $0 \leq \alpha<1$ and the disturbance term $e_{t}$ is distributed with mean zero and a finite standard deviation that is small relative to the range of neighborhood average incomes. For expositional purposes, we will focus our attention on neighborhoods with equilibrium income $x^{*}=0$. These neighborhoods will be described as "declining" neighborhoods, since their average incomes will generally be declining when the disturbance terms are small. For such neighborhoods, equation 1 is more conveniently rewritten as:

2) $\quad x_{t}=\alpha x_{t-1}+e_{t}$.

The [0,1] range on $x_{t}$ is an absorption barrier, so that large magnitude disturbances in drive neighborhood average income to one or zero, but not past. However, we assume that the spread of the disturbance term is small enough that such absorption is relatively uncommon. The analysis will focus on the set of neighborhood average incomes for

\footnotetext{
${ }^{14}$ This simple distribution generalizes to any two incomes, which can be thought of as "before" and "after" incomes. The assumption in the model will thus be that neighborhoods tend towards a perfectly segregated equilibrium.
} 
which no neighborhood reaches the barrier due to extreme disturbances. ${ }^{15}$ The parameter $\alpha$ captures the speed of adjustment towards equilibrium. The naïve interpretation of the fundamental models implicitly assumes that $\alpha=0$ : that neighborhoods instantly reach equilibrium and that cross-sectional analysis thus yields meaningful estimates of equilibrium income mixing. Over very long time periods with very rare changes in equilibrium use this may be a reasonable assumption, but over the ten year horizon offered by census data, it would seem less reasonable. Neighborhood transitions take time, and are common. On the other hand, $\alpha=1$ implies that neighborhood incomes (and thus neighborhood income mixing) are stable at any level: there is no trend towards some other equilibrium level. We will follow Tiebout, Alonso and Schelling and assume that $\alpha<1$. The results below focus on the case of a declining neighborhood, but all the results hold qualitatively for the case of gentrifying neighborhoods.

With these very simple dynamics, it is possible to show some key patterns. The first is that, on average, the variance in neighborhood income will be falling over time, or that $\sigma_{t}<\sigma_{t-1}$. To see when this would be the case, we express the inequality in terms of the same parameters:

$$
\sigma_{t}=\left(\alpha x_{t-1}+e_{t}\right)\left(1-\alpha x_{t-1}-e_{t}\right)<\left(x_{t-1}\right)\left(1-x_{t-1}\right)=\sigma_{t-1} .
$$

Some algebraic manipulations yield:

$$
\text { 4) } \quad\left(1-\alpha^{2}\right) x_{t-1}<(1-\alpha)-2 \alpha e_{t}+\left(e_{t}^{2}-e_{t}\right) x_{t-1}^{-1} \text {, }
$$

\footnotetext{
${ }^{15}$ Including the excluded neighborhoods into the analysis complicates matters considerably. Their inclusion would weaken the first result, but should have no effect on the second two results. The results thus hold for the broad middle of neighborhoods, but not for neighborhoods having already reached the extremes of the income distribution.
} 
which does not yield immediately to analysis because the relationship will depend on the disturbance term. However, taking the expectation of each side (across neighborhoods) yields a more manageable relationship:

5) $\quad E\left(x_{t-1}\right)<\frac{1-\alpha}{1-\alpha^{2}}+\frac{E\left(e_{t}^{2} x_{t-1}^{-1}\right)}{1-\alpha^{2}}$.

This says that, on average, neighborhood income variance will be decreasing with time as long as average income in the earlier period is below a threshold level that depends on the speed of adjustment plus a positive term involving the disturbance term. The first term on the r.h.s. represents the "deterministic" part of the relationship between prior and subsequent variances in income, while the second term represents the contribution of the random disturbances to the changes in standard deviation. This second term implies that, even if there were no deterministic trend in neighborhood income variance (if $\alpha=1$ ), the random noise in the system will create a declining trend. This is an important factor to which we will return in the empirical section.

It is instructive to focus on the deterministic portion of this system by assuming the disturbance term is identical to zero. The deterministic part of the threshold ranges from one (when $\alpha=0$ ) to a little over $1 / 2$ (as $\alpha$ approaches 1 ). For a given value of $\alpha$, neighborhoods with higher incomes will gain in income variance, while lower incomes will experience declines in income. This is a result of the non-monotonic relationship between average income and income variance. Since this result describes neighborhoods with incomes declining towards an equilibrium income $x^{*}=0$, it is likely that the average $x_{t-1}$ will be below $1 / 2$, so that inequality 5 holds. A parallel result holds for gentrifying neighborhoods. This result means that, on average, neighborhoods should be observed to lose income variance over time. 
Another result of this basic set-up is that larger changes in average income will be associated with larger subsequent levels of income mixing, or neighborhood income variance. In other words, if we observe highly mixed neighborhoods, it is likely the case that this mix is the result of neighborhood transition rather than evidence of a stable mixed-income neighborhood. To show this result, we note that equation one implies that $x_{t-1}=\left(x_{t}-e_{t}\right) / \alpha$ and that the change in neighborhood average income, $\Delta x_{t}=x_{t}-x_{t-1}$. We substitute $x_{t-1}$ into $\Delta x_{t}$ and solve this equation for $x_{t}$, yielding an equation for current period average income in terms of the change in average income, the disturbance term and $\alpha$. Plugging this equation into the formula for neighborhood income variance gives the following equation:

6) $\sigma_{t}=x_{t}\left(1-x_{t}\right)=\frac{\alpha \Delta x_{t}+e_{t}}{\alpha-1}\left(1-\frac{\alpha \Delta x_{t}+e_{t}}{\alpha-1}\right)=\frac{\alpha \Delta x_{t}+e_{t}}{\alpha-1}-\frac{\left(\alpha \Delta x_{t}+e_{t}\right)^{2}}{(\alpha-1)^{2}}$.

Because this equation holds for declining neighborhoods, and we are interested in the magnitude of change in average income, equation 6 becomes: ${ }^{16}$

7) $\sigma_{t}=\frac{e_{t}-\alpha\left|\Delta x_{t}\right|}{\alpha-1}-\frac{\left(e_{t}-\alpha\left|\Delta x_{t}\right|\right)^{2}}{(\alpha-1)^{2}}$

We are interested in the relationship between income variance and the change in average income, so we evaluate when

8) $\frac{\partial \sigma_{t}}{\partial\left|\Delta x_{t}\right|}=\frac{-\alpha}{(\alpha-1)}+\frac{2 \alpha}{(\alpha-1)^{2}}\left(e_{t}-\alpha\left|\Delta x_{t}\right|\right)>0$,

which reduces to

\footnotetext{
${ }^{16}$ Equation 7 assumes that the change in average income is negative in degentrifying neighborhoods, which will be true for a large majority of such neighborhoods. Very extreme, positive disturbance terms could occasionally cause degntrifying neighborhoods to experience temporary increases in income, in which case the results derived below would not hold.
} 
9) $\quad 2\left(e_{t}-\alpha\left|\Delta x_{t}\right|\right)>\alpha-1$.

This inequality is difficult to evaluate because it depends upon the disturbance term. Taking the expectation of each side and rearranging yields:

10) $2 E\left(\left|\Delta x_{t}\right|\right)<\frac{1-\alpha}{\alpha}$.

Thus, on average, greater neighborhood change will be associated with greater subsequent income mixing whenever the expected magnitude in the change in income is less than a threshold which depends on the speed of transition. This threshold is again picking up the non-monotonic relationship between average income and income variance. Will the inequality hold? We can use the deterministic part of the relationship between previous period average income and changes in average income to get a sense for the validity of this inequality. The lower $\alpha$, the more easily inequality 10 will be satisfied. For instance, if $\alpha=1 / 2$ or less, inequality 10 holds for any average previous-period income less than one. ${ }^{17}$ As $\alpha$ increases towards unity, the r.h.s. of inequality 10 decreases, but so does the l.h.s. (because the expected change will be less when $\alpha$ is closer to one). However, the l.h.s. does not decrease as quickly, so that for higher $\alpha$, average incomes must be lower (thus reducing further the expected change in income). If $\alpha=2 / 3$, at least a quarter of residents must be poor $\left(x_{t-1}<.75\right)$ for the inequality to hold. For $\alpha$ equaling $3 / 4$ and 9/10, at least one third or four ninths of the neighborhood must be poor, respectively. No value of $\alpha<1$ requires more than half of the residents of the neighborhood be poor for inequality 10 to hold. Because this result concerns neighborhoods with incomes declining towards $x^{*}=0$, it is likely that these neighborhoods will have average incomes

\footnotetext{
${ }^{17}$ We know this because if $\alpha=1 / 2$ the r.h.s. of inequality 10 equals 1 , while $E\left(\left|\Delta x_{t}\right|\right)=\alpha E\left(x_{t-1}\right)$, which cannot be greater than $1 / 2$ when $\alpha=1 / 2$.
} 
less than $1 / 2$, so that inequality 10 holds. A parallel result holds for gentrifying neighborhoods. This result means that on average neighborhoods experiencing large changes in average income will also be observed to have more income mixing.

A final result concerns the relationship between previous-period income mixing and subsequent changes in neighborhood average income. We might expect this relationship to hold in reality because if mixed income neighborhoods are unstable, highly mixed neighborhoods will be likely candidates for rapid demographic shifts as either rich or poor flee the neighborhood. In our highly stylized model, we show this by expressing the magnitude change in average income in terms of the previous-period variance in income. First we must rewrite the formula for neighborhood income variance.

$$
\sigma_{t-1}=x_{t-1}\left(1-x_{t-1}\right)=.25-\left(x_{t-1}-.5\right)^{2}
$$

This formulation is valid for the range of $x_{t-1}$. Unfortunately, solving equation 11 for $x_{t-1}$ does not yield a function.

12) $\quad x_{t-1}=\left\{\begin{array}{l}\left(.25-\sigma_{t-1}\right)^{1 / 2}+.5 \quad \text { for } x_{t-1}>.5 \\ -\left(.25-\sigma_{t-1}\right)^{1 / 2}+.5 \text { for } x_{t-1}<.5\end{array}\right.$

Thus, the sign of the derivative will depend on $x_{t-1}$ as well:

$$
\frac{\partial x_{t-1}}{\partial \sigma_{t-1}}= \begin{cases}-\frac{1}{2}\left(.25-\sigma_{t-1}\right)^{-1 / 2}<0 & \text { for } x_{t-1}>.5 \\ \frac{1}{2}\left(.25-\sigma_{t-1}\right)^{-1 / 2}>0 & \text { for } x_{t-1}<.5\end{cases}
$$

Because $\left|\Delta x_{t}\right|=\left|x_{t}-x_{t-1}\right|=\left|(\alpha-1) x_{t-1}+e_{t}\right|$, it is possible to express the derivative of the absolute change in average income with respect to the beginning period variance in income. 
14) $\frac{\partial\left|\Delta x_{t}\right|}{\partial \sigma_{t-1}}=\frac{\Delta x_{t}}{\left|\Delta x_{t}\right|} \frac{\partial \Delta x_{t}}{\partial x_{t-1}} \frac{\partial x_{t-1}}{\partial \sigma_{t-1}} \begin{cases}<0 & \text { for } x_{t-1}>.5 \\ >0 & \text { for } x_{t-1}<.5 .\end{cases}$

The signs are implied by equation 13 , the fact that the first quotient is negative for declining neighborhoods (for the average disturbance term) and the fact that $(\alpha-1)<0$. Again, the importance of previous period income on the sign of the result comes from the non-monotonic relationship between average income and income variance.

What the result says is that for richer declining neighborhoods, high variance will be associated with smaller changes in average income, but that in poorer declining neighborhoods high variance will be associated with larger changes in income. Because these results concern neighborhoods trendening towards $x^{*}=0$, it seems reasonable that the majority of them would start the period with $x_{t-1}<1 / 2$, so that the average effect (for declining neighborhoods) would reflect the results for poor neighborhoods more closely than the results for richer neighborhoods. A parallel result holds for gentrifying neighborhoods so that the average effect of mixing on subsequent income changes will be positive.

It is important to be clear about what has just been done. The above schematic of neighborhood dynamics is purely mechanical. The model as laid out makes no behavioral assumptions: these assumptions were laid down over 30 years ago by Tiebout, Alonso and Schelling. Nor does the model tell us what happens to real neighborhoods in real cities: that is an empirical matter. What the model does is take a reasonable representation of the Tiebout, Alonso and Schelling models (that neighborhoods will tend to move towards their equilibrium use), and show that allowing for a gradual transition towards equilibrium ( $\alpha>0$ ) should cause some regularities to be observed in the data. 
Note that if mixed income neighborhoods could be sustained $(\alpha=1)$, the last two results would not hold. ${ }^{18}$

The above sketch of neighborhood dynamics has also offered some insight into the types of variables we might seek to account for in the empirical treatment below. In the results above, the sign of the relationship usually depended on previous period average income and on $\alpha$. Thus when implementing the model empirically, we will want to control for previous-period income and factors that might affect the stability of a neighborhood. The results above also depend on essentially zeroing out the error terms. While this is fair if we assume that the error term is uncorrelated with any other variable in the analysis, in actuality it is quite possible that such demographic shocks could be correlated with other variables, and so we will need to control for such factors as best we can.

\section{Empirical Model.}

To asses the stability of mixed income neighborhoods in American cities, I conceptualize neighborhoods as behaving according to a partial adjustment model similar to that in section III, but with a focus on income mixing instead of income levels. This model assumes that each neighborhood has an equilibrium level of mixing, which we cannot observe, and that as time passes the neighborhood approaches this level of mixing, but experiences random shocks along the way. In symbols, this idea is expressed as:

$$
\sigma_{i t}=\sigma_{i t-1}+\alpha^{\prime}\left(\sigma^{*}-\sigma_{i t-1}\right)+\varepsilon_{i t} .
$$

\footnotetext{
${ }^{18}$ The first result, that variance will decline on average in any neighborhood, would still hold in the presence of the random disturbance term. However, purging this relationship of the random component would create a situation in which the neighborhood variance in income does not change from period to period. The purgation of the random disturbances is an issue taken up in the empirical section.
} 
In equation 15, $\sigma$ is a measure of within-neighborhood income mixing. The indexes $i$ and $t$ index neighborhoods and time, respectively, $\varepsilon_{i t}$ represents the random shock to income mixing that neighborhood $i$ experiences at time $t$ and $\alpha^{\prime}$ represents the speed of adjustment to equilibrium (the proportion of the difference between previous period income mixing and the equilibrium level of mixing that the adjustment process eliminates during a time period). ${ }^{19}$

Another way to write equation one that brings out the intuition a bit better is:

$$
\Delta \sigma_{i t}=\sigma_{i t}-\sigma_{i t-1}=\alpha^{\prime}\left(\sigma^{*}-\sigma_{i t-1}\right)+\varepsilon_{i t} .
$$

In equation 16, we look at the situation in terms of changes in the neighborhood's income diversity. It says that changes in income mixing will be related to how far from the equilibrium level of mixing the neighborhood was in previous periods. If $\alpha^{\prime}$ were one, it would mean that every period the neighborhood gets back to its long run equilibrium, ignoring the random shocks it would experience. If $\alpha^{\prime}$ were zero, it would mean that there is no tendency for neighborhoods to move towards some other value. In such a case the concept of the "equilibrium" represented by $\sigma^{*}$ would be meaningless: there is no adjustment, and the current level (in time $t$ or $t-1$ ) is essentially the equilibrium, both in the short and the long run sense.

I interpret the idea of stable income mixing as being represented by $\alpha^{\prime}=0$ (or $1-\alpha^{\prime}$ $=1$ ). This implies that there is no adjustment towards any equilibrium, and the time path of neighborhood income mixing follows what is called a "random walk" dominated completely by unpredictable shocks. The idea of a random walk is not usually associated

\footnotetext{
19 The relationship between $\alpha$ and $\alpha^{\prime}$ is complicated. While the exact functional form is not worked out here, I can say that $\alpha$ will be positively related to (1- $\left.\alpha^{\prime}\right)$. Thus, the "naïve" interpretation of Alonso, Tiebout and Schelling $(\alpha=0)$ corresponds to $\left(1-\alpha^{\prime}\right)=0$ (or $\left.\alpha^{\prime}=1\right)$ and the "stable neighborhood incomes and mixing” assumption $(\alpha=1)$ corresponds to $\left(1-\alpha^{\prime}\right)=1$ (or $\left.\alpha^{\prime}=0\right)$.
} 
with stability. ${ }^{20}$ This, however, is the most policy-relevant view of the stability of mixed income neighborhoods. If $\alpha^{\prime}=0$, and income mixing can be increased in a neighborhood (e.g. through a policy intervention), that increase in neighborhood mixing will persist into the future, not dissipate over time. The "no adjustment" model $(\alpha=0)$ means that today's level of income mixing is essentially equilibrium. The naïve view focuses instead on a neighborhood's ability to achieve the new equilibrium extremely quickly and is represented by the "complete adjustment" model with $\alpha=1 .^{21}$ If the actual level of equilibrium mixing is large, then this would represent stable mixing. Complete adjustment means that the level of income mixing is governed by a strict equilibrium, and that any movement away from this equilibrium will be corrected within one time period. Any additional income mixing achieved by policy intervention will be transitory in the extreme.

This paper focuses on a slight variation of equation 15:

$$
\sigma_{i t}=\alpha^{\prime} \sigma^{*}+\left(1-\alpha^{\prime}\right) \sigma_{i t-1}+\varepsilon_{i t} \text {. }
$$

Equation $15^{\prime}$ begins to look somewhat like a regression equation. However, because $\sigma^{*}$ is not observed (and is in fact not identified if $\varepsilon_{i t}$ has positive expectation, as we might expect when income mixing is defined to be non-negative). For statistical purposes, a number of possible predictors of income mixing levels, $X$, stand in for it.

\footnotetext{
${ }^{20}$ One problem with random walks in long time series is that the variance of the variable increases to infinity as the amount of time approaches infinity. In the present context with only two time periods, this is not too unattractive. There is no reason why the variance of income mixing cannot be increasing over a ten or twenty year time span. Rosenthal (2008) estimates the relationship between changes in neighborhood income over longer time spans and rejects the unit root. Rosenthal's result indicates that neighborhoods cycle through periods of relative affluence and poverty over very long time periods, but his results do not speak to the issue of whether neighborhoods can sustain income mixing around this changing average.

${ }^{21}$ However, such a view does not address what this equilibrium level of mixing is and how it would be measured econometrically.
} 


$$
\sigma_{i t}=\beta_{0}+\beta X+(1-\alpha) \sigma_{i t-1}+\varepsilon_{i t} .
$$

It is important to note that factors that increase equilibrium mixing and factors that increase the random shocks to neighborhood mixing levels cannot be separately identified in this framework since $\beta_{0}$ will soak up any non-zero expectation in the error term. Thus, our assessment of the stability of income mixing rests on our estimates of $1-$ $\alpha^{\prime}$, with $1-\alpha^{\prime}=1$ representing stability.

There are several reasons why we might not trust the OLS estimate of (1- $\left.\alpha^{\prime}\right)$. The theoretical sketch in part III of this paper suggested the need for instrumentation through the "random" component in equation 5, but there are other reasons to be suspicious. One is measurement error. If $\sigma_{i t-1}$ is measured with error, then the estimate of (1- $\left.\alpha\right)$ will be biased towards zero. It could also be the case that there is serial correlation in the neighborhood- and time-specific random shocks $\left(E\left(\varepsilon_{i t} \varepsilon_{i t-1}\right)>0\right)$. This would cause $\sigma_{i t-1}$ to be correlated with the error term in a regression along the lines of equation 17. To deal with these possibilities, we instrument for $\sigma_{i t-1}$ with $\sigma_{i t-2}$. Under the assumptions laid out above, this procedure gives a consistent estimate of (1- $\left.\alpha^{\prime}\right)$.

The IV strategy in the previous paragraph will not be appropriate if the serial correlation spans more than one period, for instance, if $\varepsilon_{i t}$ is correlated with $\varepsilon_{i t-2}$. Such correlation could occur if our control variables $X$ in equation 17 do not fully capture equilibrium and disequilibrium contributors to neighborhood income mixing so that neighborhoods have a neighborhood-specific component of the error term, if there is measurement error that is correlated across time periods or if the random shocks are correlated across more than one decade. I use two techniques to deal with this possibility. First, to deal with the possibility of correlated measurement error or longer 
time-span serial correlation, I instrument for $\sigma_{i t-1}$ with a battery of $t-2$ predictors of $\sigma_{i t-2}$ (such as median income and neighborhood demographics). I also estimate equation 17 in differences to eliminate any neighborhood-specific unobserved effects. In such a differencing strategy, the lagged difference will be correlated with the error term by construction, so in all these models I instrument for the lagged difference in income mixing $\left(\sigma_{i t-1}-\sigma_{i t-2}\right)$ with either the twice-lagged level of income mixing $\left(\sigma_{i t-2}\right)$ or the predictors of $\sigma_{i t-2}$ mentioned above. As the results of any instrumental variables estimation hinge entirely on the validity of the assumptions used to justify the instruments, the results section below will present results from a variety of IV strategies, with different variables included or excluded in the second stage equation.

\section{Data.}

An estimation of equations 17 requires panel data on neighborhood demographics. Until recently, such data was not available because the census changes tract boundaries for each census. This paper uses proprietary data compiled by Geolytics which use GIS programs to compute old census demographic information in census tracts and block groups as they were drawn in the 2000 Census. This allows for the comparison of an area's demographics across time. We use the census block group as our unit of analysis because Coulton et al. (2004) find that census block groups most closely match their respondents' conception of their own "neighborhood," at least in their sample which included only residents of dense urban neighborhoods.

The most natural measure of neighborhood income mixing would be the withinneighborhood standard deviation of income. This measure, however, is extremely strongly correlated with average income. To mitigate this issue, I use four different 
measures of income mixing. The first is simply the log of the standard deviation of income within a neighborhood $(\ln \sigma)$. This measure is not as correlated with median income, and its distribution is not as skewed as raw standard deviation of income. The next measure I examine is the coefficient of variation of income (CoVa), which is the standard deviation divided by the average (in this case, it is divided by the median income, not the average). This measure is not as skewed as the standard deviation. It also reports income spread as a proportion of the central value of the neighborhood income distribution. This is desirable since it might be the case that at high incomes a dollar's difference between neighbors' incomes does not count as much as at lower incomes. However, because median income enters directly into the calculation of this measure, a correlation with median income persists (although it is smaller in absolute value than the correlation between neighborhood standard deviation and median income).

As both the above measures ( $\ln \sigma$ and $\mathrm{CoVa}$ ) are correlated with median income, there are potential problems in the interpretation of the variables. Do changes in them represent changes in mixing or changes in medians? I also run models using the standardized residuals from regressions of standard deviation of income and CoVa on contemporaneous median income. By construction, these variables ( $\sigma$-resi and CoVaresi) have mean of zero, standard deviation of one and are completely uncorrelated with median income.

The rest of the variables used in the analysis attempt to capture the possible equilibrium level of mixing or random shocks to income mixing. First, each metropolitan area has developed along its own history, guided by state and local policies specific to it, and each possessing its own culture and constraints. These metropolitan-specific factors 
could influence the equilibrium level of mixing in a neighborhood, or the amount of random disturbance to neighborhoods. To eliminate this possibility, every regression reported in this paper (including the most parsimonious and the regressions in differences) contains 264 metropolitan fixed effects. Two more important variables, included in most of the regressions, are the block group's median income relative to the median income of the average block group in a metropolitan area (Income) and the magnitude of the change in neighborhood median income over the preceding decade, relative to the metropolitan average change, and standardized to the metropolitan income

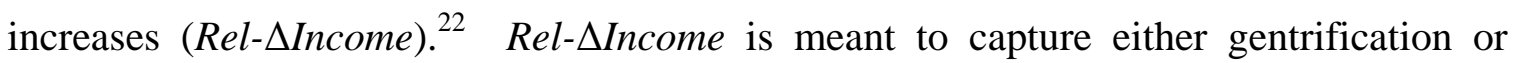
neighborhood deterioration, and is always greater than zero.

Additional variables meant to capture differences in the equilibrium amount of mixing or random disturbance include neighborhood demographic characteristics, housing characteristics and geographic factors. The demographic factors included are the proportion of the BG population that is college educated (College); the proportion that are high school drop outs (DropOut); proportion of households with children (Children); proportion white, non-Hispanic (White); proportion of families with at least one working adult in residence (Workers); percent of families below 150\% of the official poverty line (Poverty); and the proportion of households living in the same house as five years prior to the census in question (Stayers). Housing characteristics include the owner occupancy rate (Owners), the median year of construction of neighborhood residences (YearBuilt), the residential population density and its square (Density and Density ${ }^{2}$ ) and the median

\footnotetext{
${ }^{22}$ Rel $\Delta$ Income $=0$ signifies income growth in the neighborhood was exactly the same as income growth in the metropolitan area. Rel Income $=1$ signifies that neighborhood income growth was twice as fast as the metropoliktan area's groth, or zero ( $100 \%$ more or less than metropolitan growth). Rel $\Delta$ Income $=.5$ signifies income growth about $150 \%$ or $50 \%$ as fast as the average block group in the metropolitan area.
} 
value of residential housing units and its square (Value and Value ${ }^{2}$ ). The geographic component is the log of the linear distance to the nearest historic center of a populated place as defined by the National Atlas (Distance). ${ }^{23}$ When these variables vary with time (as is the case for all the variables except Distance), they are generally measured at each census in 1980, 1990 and 2000, which allows for the empirical strategy described above to be implemented.

The descriptive statistics for each set of variables are presented in Appendix A. In passing, note that the average standard deviation of household income in a block group is about 34,000 , while the standard deviation of the whole country, computed in the same way, is about 42,500 . This suggests that on average block groups are more homogenous than the country as a whole, although they exhibit substantial heterogeneity: by Jargowsky's index, only 20 percent of income variance comes across block-group, as opposed to within block groups. Without further delay, we can move to the results.

\section{Main Results.}

Tables 1-3 present the results for each of the measures of income mixing described above. These tables present only the coefficients on the primary variables: income mixing, and relative levels and changes in median income. For the most part, the coefficients on the other control variables have easily interpretable signs. These results are available from the author on request.

\footnotetext{
${ }^{23}$ This measure is meant to capture commuting time, or the rent gradient associated with longer commutes from the Alonso/Muth model. These distances are not to the central metropolitan CBD, but to the center of any populated place. This allows cities to have multiple employment centers. More information on the places used can be found at: http://nationalatlas.gov/mld/citiesx.html .
} 
Table 1 reports the results on the three primary variables of interest under very optimistic assumptions of no endogeneity in levels or differences. Models I-IV report OLS results, while columns V-VIII report results of simple OLS models run on the differences of all the variables. ${ }^{24}$ Panels A, B, C and D report the results for the four different measures of income mixing (ln $\sigma$, CoVa, $\sigma$-resi and CoVa-resi, respectively). The results are consistent across all four measures. In levels, the relationship between current and lagged income mixing is greater than zero but significantly less than one in every case. The first difference results theoretically give estimates of the same parameter, but these coefficients are uniformly negative and significant. However, as discussed above, it is not appropriate to interpret these coefficients as representing the relationship laid out in the empirical model. If one views this evidence cross-sectionally, however, it can be taken as meaning that neighborhoods that had unexpectedly large increases in income mixing one decade tend to have unexpectedly large decreases in income mixing the next. In the sense of a conditional average, this statement is a true description of the situation, but can only be taken so far in light of the econometric issues raised above. $^{25}$

Table 2 presents a variety of regressions which attempt to deal with the endogeneity plaguing the results of Table 1 through the application of instrumental variables. Columns I-IV present results using 1980 levels of income mixing as the instrument. Columns V-VIII present results using 1980 levels of correlates of income mixing as instruments in a Two Stage Least Squares estimation. These estimates rely on

\footnotetext{
${ }^{24}$ Running such a regression is not appropriate in this context because of the dynamic nature of the model. These results are presented only for discussion.

${ }^{25}$ The results in columns V-VIII also imply that areas that had unexpectedly large decreases in income mixing in one decade will have unexpectedly large increases in income mixing the next.
} 
the validity of the omission of these 1980 neighborhood demographic characters from the equation predicting year 2000 income mixing. However, these models usually fail overidentification tests quite spectacularly. ${ }^{26}$ This is because neighborhoods are highly dynamic, and past conditions probably have a present effect on outcomes, even after more than a decade.

The rest of Table 2 attempts to address this problem through less severe assumptions. The remaining columns revert to the IV strategy of columns I-IV, but control for 1980 neighborhood demographics and housing characteristics (columns IXXII). Columns XIII, XIV and XV add 1990 neighborhood demographics and housing characteristics to the set of controls. While the validity of the instrument cannot be formally tested, including the battery of 1980 and 1990 neighborhood characteristics as included instruments makes the exclusion restriction more plausible.

The results for these instrumental variables regressions are not as consistent across mixing measures, but a few general comments can be made. First, generally, the coefficients on lagged income mixing are significantly positive and less than one. Second, the addition of the control variables (year 2000 demographics and housing characteristics) tends to pull the coefficient on lagged income mixing downward, towards zero. This is especially true for the coefficient of variation based measures (CoVa and CoVa-resi). While there are several individual mixing coefficients that are equal to or greater than one (for CoVa-resi and $\ln \sigma$ ), these instances happen only in the first eight columns with the naïve IV and 2SLS strategies, which are suspect in terms of consistency. The coefficients for both these variables come down significantly below

\footnotetext{
${ }^{26}$ The p-value on the overidentification test (using Hansens J-statistic) are all less than 0.001 . However, this is partly being driven by large sample size. There exist randomly drawn sample sizes where the coefficients in the second stage retain their significance but the models pass this test.
} 
one in the final eight columns of Table 2, where we can be more confident in the estimation strategy.

Table 3 reports results based on difference equations, which theoretically estimate the same coefficient. As was discussed above, there is a built-in negative relationship between current and lagged changes in any variable. The estimates in table 3 correct for this in a variety of ways. Columns I-IV instrument for lagged changes in income mixing using the 1980 levels of neighborhood demographics and housing characteristics. These specifications fail diagnostic tests for overidentification. ${ }^{27}$ The remainder of Table 3 presents results from models attempting to address this problem. Columns V-VII use the same set of instruments as columns I-IV, but control for a set of lagged changes in the second stage equation. These specifications also fail the test for overidentification. The final columns (VIII-X) use a specification inspired by the final columns of Table 2. These specifications revert to a standard instrumental variables approach, using 1980 income mixing as the instrument, but retaining the array of lagged differences used as controls in columns V-VII, and adds the array of 1980 controls (which were instruments in the first seven columns of Table 3). This instrumental variables strategy cannot be formally tested, but the large set of included instruments gives the exclusion restriction face validity.

The results in Table 3 show that every coefficient on the lagged mixing variables is significantly less than one. The somewhat less troubling possibility that the coefficient is less than zero is not as easily rejected. $\ln \sigma$ is significantly less than zero in all of the first seven columns. However, these are the models which produce the most suspect estimates. The results in the final column, with all possible controls, reproduce a very

\footnotetext{
${ }^{27}$ However, as per footnote 26, above, this is partly driven by sample size.
} 
significantly positive coefficient that is consistent with the results for many of the other variables and specifications. The coefficient on CoVa-resi varies around zero in the first four columns, even becoming significantly so in one specification (although the magnitude of this negative coefficient is tiny compared to those for $\ln \sigma$ ). In the "better" specifications of columns V-X, this coefficient stays positive consistently, but not significantly.

What is the meaning of the over 130 models just reported? I take these results to be strong support of the three canonic models of income segregation in a realistic dynamic setting. Across the models, there can be almost no doubt that the coefficient in the regression equations is less than one. While we may worry that the IV strategy does not completely purge the coefficients of endogeneity bias, the range of estimates is so far from one that it seems highly unlikely that true relationship approaches one. Given that it is not possible to actually measure the equilibrium level of mixing, we must take our evidence from the dynamics of income mixing. In the context of the partial adjustment model described above, the less-than-one coefficient on lagged income mixing signifies two things. First, if a neighborhood strays from equilibrium, it will return towards it gradually. Second, most neighborhoods do not start out in 1990 at equilibrium. Ideally, one would show that this equilibrium adjustment is mainly down-wards, but such a demonstration is not possible because there is no way to identify the equilibrium level unless one assumes that the random components are mean zero. Since income mixing cannot be negative, it is not likely the case that its random shocks are zero in expectation. In such a case, economists are left to theory to interpret the meaning of the average amount of mixing. Does it represent equilibrium forces for mixing or disequilibrium 
disturbances? In the present case, the weight of theory is squarely on the side of disequilibrium. The dynamic behavior of mixed income neighborhoods supports this conclusion because mixing induced by policy or other means will evaporate over the following years.

\section{Additional Results}

The theoretical sketch in section III suggested some additional patterns in the data if income mixing is unstable. The sketch suggested that these relationships as well as the one tested in section VI should be conditional on initial levels of income in the neighborhood. It also suggested a positive partial correlation between income mixing and subsequent changes in relative income, and a positive relationship between income changes and subsequent mixing. This section discusses these predictions and results in broad outlines. First, I discuss the sensitivity of the results in section VI to the inclusion of various interaction terms. Then, I discuss the relationship between previous changes in income and subsequent income mixing, both with and without the interaction terms. Finally, I discuss the relationship between previous income mixing and subsequent changes in income with and without the interactions.

\section{A. Adding interactions to the mixing equation.}

The theoretical sketch in section III suggested that the relationship between lagged and current income mixing is conditioned by a neighborhood's income level. In this subsection, I discuss a battery of models run with such interactions. For every full regression reported in tables 1-3, I ran parallel models with an interaction between lagged income mixing and relative neighborhood income. I also ran a set of models which included an 
interaction between recent neighborhood changes in relative income and lagged income mixing, and a set of models which included both these interactions. ${ }^{28}$ While these results are too numerous to report, I describe the results here to provide a sense of the robustness of the results to these changes in specification.

The interaction terms are significant in a bit over half the models, but there is not a strong pattern in their sign. Depending on the measure and the identification strategy, the sign of the interaction between lagged mixing and relative income switches signs and significance. In the preferred models (using the IV strategy and the full set of controls in first differences), this interaction tends to be insignificant. The interaction between lagged income mixing and recent relative changes in neighborhood income is often significant and displays a fairly consistent pattern across specifications, especially for the residual-based measures. For the residual-based measures, this interaction is generally significant and negative, except in the preferred model, where it is significant and positive across all four measures of mixing. In the models where both interaction terms are included, the results in the preferred model back this conclusion up: the interaction with changes in neighborhood income is generally significant and positive. Taking these results together, it means that the stability of income mixing is not strongly affected by pre-existing income levels, but is increasing in changes in income.

The substantive importance of these interactions in terms of affecting the stability of mixed income neighborhoods is minimal. Although neighborhoods experiencing larger changes in relative income are more stable (in terms of income mixing), the combined effect of lagged mixing on current mixing is almost always significantly less

\footnotetext{
${ }^{28}$ In the IV models, twice-lagged interactions were used as instruments for the interaction terms. In the 2SLS models, the same vector of 1980 predictors of 1980 income mixing served as excluded instruments for the interaction terms.
} 
than one. This means that across all neighborhood types (high- and low-income, stable and quickly changing), income mixing gained in one period tends to erode over ensuing time periods. In some cases and for some types of neighborhoods, the total effect is insignificantly different from zero, meaning that any additional income mixing induced in one period will disappear entirely over the ensuing decade. However, these zero effects occur only for very limited ranges of neighborhood types, and never in the preferred specification. The general message of this sub-section is thus that the results reported in section VI are extremely robust to the inclusion of interaction terms in the specification. B. Income changes relationship to subsequent mixing.

The relationship between previous changes in income levels and subsequent income mixing in the absence of any interactive effects can be seen in tables 1-3. There, we see that the un-interacted relationship is generally positive as hypothesized except for the residual-based standard deviation measure ( $\sigma$-resi), which is generally negative and significant. Furthermore, in the final column of table 3, for the ln $\sigma$ measure of income mixing, the coefficient on income changes is significantly negative. Because this last column represents the preferred model, this switch is significant. The pattern which emerges is that standard-deviation-based measures of income mixing decrease with neighborhood income changes, while coefficient-of-variation-based measures increase with these changes. The addition of the interaction term between previous period relative income and income mixing does not alter this pattern: $\ln \sigma$ and $\sigma$-resi fail to support the pattern suggested in section III, while CoVa and CoVa-resi do exhibit that pattern.

When we add an interaction between relative income changes and lagged income mixing, the results become more complicated because the effect of income changes on 
subsequent mixing will now depend on pre-existing levels of income mixing. The sign of this interaction term is somewhat unstable, but as discussed above, tends towards the positive, especially in the preferred specification. This means that neighborhood income changes lead to more mixing the more mixed a neighborhood is to begin with. For the non-residual-based measures (in the preferred specification), this interactive effect is enough to change the total effect of income changes from significantly negative to significantly positive (in the range of the data). However, for the two residual-based measures, the pattern form the un-interacted results persists: $\sigma$-resi is affected negatively by income changes and CoVa-resi is affected positively, whatever the pre-existing level of income mixing.

These results are interesting for a number of reasons. First, the significance of the interaction terms suggests that the effects income changes (gentrification of degentrification) on mixing depend on the amount of income mixing that exists before the changes occur. Such heterogeneous effects suggest that a rich and complicated process drives (and is driven by) neighborhood change. Furthermore, the heterogeneity of results across mixing measures - with the coefficient-of-variation-based measures supporting the theory and the standard-deviation-based measures undermining it - suggest that income mixing itself is an extremely rich and difficult-to-measure characteristic of neighborhoods. In and of itself, the difficulty in measuring income mixing will be an important barrier to any successful policy meant to encourage income mixing. C. Mixing's relationship with subsequent income changes.

Models were also run with relative change in neighborhood income from 1990 to 2000 as the dependent variable to detect whether the hypothesized positive relationship 
between previous income mixing and subsequent changes in income was borne out in the data. ${ }^{29}$ In the models run without interactions, the strength of these relationships depends on the measure of income mixing used and the specification. Using simple OLS estimation, the hypothesized positive relationship exists for all measures except $\ln \sigma$, which has negative insignificant coefficients. As we move to instrumental variable and two-stage least squares strategies similar to those used in the income mixing equations, this pattern generally persists, with positive effects for all measures of mixing except $\ln \sigma$, but sometimes these positive coefficients drop into insignificance for $\sigma$-resi.

The theoretical sketch suggested that this positive relationship should be conditioned by previous period income of the neighborhood. I ran models predicting neighborhood income change that included the interaction between lagged mixing and lagged relative neighborhood income, both in OLS and using IV and 2SLS strategies similar to those used in the mixing regressions. The negative effects of lagged $\ln \sigma$ on subsequent income changes persists through the distribution of neighborhood incomes. The total effects of $\sigma$-resi display significant heterogeneity across estimation strategies, although all of them include substantial ranges of pre-existing incomes that yield positive total effects of mixing on subsequent income changes. For the CoVa and Cova-res measures of income mixing, the total effect is strongly positive and significant for most specifications across the entire range of pre-existing relative income levels, although there is some heterogeneity of effects. These results suggest again that the simple theoretical sketch is better-supported by the coefficient of variation measures than the standard deviation measures. The heterogeneity of effects (across neighborhoods) is also important.

\footnotetext{
${ }^{29}$ Again, these results are not reported in the interest of space. They are available from the author.
} 


\section{Summary of additional results.}

There are three primary messages that these additional results convey. First, across mixing measures and across specifications, the main results of the paper - that income mixing is not stable within a neighborhood - is shown to be robust to a number of changes in the model. Section VI showed that this result was generally robust to changes in estimation strategy and the inclusion of control variables. Here, we saw that the addition of interaction terms do not affect this general result. Across neighborhood types, the stability of mixed income communities is not strong.

The second primary result of this section is that the interaction terms generally appear to be significant, so that the stability of mixed income neighborhoods and the effects of mixed income neighborhoods on subsequent neighborhood transition will depend on the nature and possibly on the history of the neighborhood. It is difficult at this stage to be much more specific than this very broad statement because of the third primary result of this section: the measurement of income mixing can have substantial effects on the apparent processes by which income mixing and other neighborhood characteristics co-evolve. Depending on the measure of income mixing used, mixing can either be increased or decreased by neighborhood demographic change. Neighborhood demographic change, on the other hand, can either be induced or muted by preexisting income mixing. While the measurement of income mixing does not affect the central question of the paper (the results in section VI are robust to the measure chosen), our understanding of the process of neighborhood change and its relationship with mixedincome communities depends on how we measure mixing. To this, more fundamental question the present effort is mute. The appropriate measurement of income mixing 
should be linked in some way to the purported beneficial or harmful effects of such communities, to the specific goals of mixed income policies or (hopefully) to both. Such a fine-tuned understanding of the inner-workings of neighborhoods does not yet exist.

\section{Conclusion and policy considerations.}

The existence of stable, mixed-income communities has been a goal of urban planners for some time. Local housing agencies, redevelopment authorities and HUD have all offered incentives to developers to induce the development of such communities. The logic of such policies would seem to be that mixed-income communities, while preferred by all, are un-profitable because of some sort of market imperfection. Many central city governments promote their cities as places where different kinds of people mix freely on the assumption that mixed-income communities are attractive to most people.

In the face of these policy initiatives, it is important to understand how and why income mixing occurs. The lack of a solid answer represents a gaping hole in the urban economics literature. If it is the case that people really prefer to live near others of dissimilar means, but that profit-maximizing developers do not provide mixed-income housing developments, then the policies encouraging such development will be welfare enhancing.

Whatever people's preferences for income mixing per se, the results in this paper suggest that such neighborhoods are not stable. The empirical evidence presented here suggests that the economic forces at work in residence decisions, business location and/or public service provision do not allow extremely mixed neighborhoods to persist. While 
there may be an equilibrium level of income mixing, it is likely lower than the mixing we observe in our decennial census.

This is not to say that public policy has no place in encouraging mixed-income neighborhoods. There are many justifications that might cause us to put positive social value on such communities. However, as Cheshire (2007) points out, these justifications should not be taken for granted. The fact that income mixing within block groups is so substantial (over 60 per cent of the total variance in income occurs within block-group boundaries) might give planners hope that sustaining mixed-neighborhoods is not impossible. This paper suggests that there are strong forces working against a successful income-mixing policy regime. If policy intervention is able to increase income mixing in a neighborhood in one time period, it is likely that between half and 90 per cent of that additional mixing will have been sorted out of existence over the following decade, depending on the parameter estimates one finds most persuasive. This means that sustaining mixed income neighborhoods cannot be a one-shot investment. Such neighborhoods will require continued support to maintain their economic diversity. However, it is probably the case that mixed income neighborhoods are no different than any other economic equilibrium: with enough subsidies, anything can happen. The parameter estimates reported above suggest that successful income mixing strategies will entail continual support, not one-time capital investment.

The problem with such a formulation is that it is hard to define what level of mixing constitutes a successful "mixed" outcome. Since the level of mixing will be sensitive to the level of spatial aggregation (Krupka 2007), mixed-income policies are working against more than equilibrium. In the absence of workable measures of income 
mixing, or a clear sense of a reasonable goal, mixed income development policies will have a hard time striking the right balance between market distortion and the greater good.

\section{References:}

Aaronson, D. (2001). "Neighborhood Dynamics." Journal of Urban Economics 49(1): 131.

Brueckner, Jan K. and Rosenthal, Stuart S., "Gentrification and Neighborhood Housing Cycles: Will America's Future Downtowns be Rich?" (October 2005). CESifo Working Paper Series No. 1579 Available at SSRN: http://ssrn.com/abstract=852525

Cheshire, Paul (2007) "Segregated Neighborhoods and mixed communities: a critical analysis." Report for the Joseph Rowntree Foundation. Available at: http://www.jrf.org.uk/bookshop/eBooks/2066-segregation-mixedcommunities.pdf

Clapp, J.M. and S.L. Ross (2004) "Schools and housing markets: an examination of school segregation and performance in Connecticut." The Economic Journal 114(Nov.): F425-F440.

Coulton, C., T. Cook, et al. (2004). Aggregation Issues in Neighborhood Research: A Comparison of Several Levels of Census Geography and Resident Defined Neighborhoods. APPAM Fall Research Conference, Atlanta, GA.

de Bartolome, C. A. M. (1990). "Equilibrium and Inefficiency in a Community Model with Peer Group Effects." Journal of Political Economy 98(1): 110-133.

de Bartolome, C. A. M. and S. L. Ross (2003). "Equilibria with local governments and commuting: income sorting vs income mixing." Journal of Urban Economics 54(1): 1-20.

Diamond, D. B. and G. S. Tolley (1982). The economic Roles of Urban Amenities. The Economics of Urban Amenities. D. B. Diamond and G. S. Tolley. New York, Academic Press: 3-54.

Duncan, O. D. and B. Duncan (1955). "Residential Distribution and Occupational Stritification." The American Journal of Sociology 60(5): 493-503.

Farley, R. (1977). "Residential Segregation in Urbanized Areas of the United States in 1970: An Analysis of Social Class and Racial Differences." Demography 14(4): 497-518. 
Frankel, D. M. (1998). "A Pecuniary Reason for Income Mixing." Journal of Urban Economics 44: 158-169.

Helms, A. C. (2003). "Understanding Gentrification: an empirical analysis of the determinants of urban housing renovation." Journal of Urban Economics 54: 474498.

Jargowsky, P. A. (1996). "Take the Money and Run: Economic Segregation in U.S. Metropolitan Areas." American Sociological Review 61(6): 984-998.

Jargowsky, P. A. (2003). Stunning Progress, Hidden Problems: The Dramatic Decline of Cencentrated Poverty in the 1990s. Living Cities Census Series. Washington, D.C., Center on Urban and Metropolitan Policy, The Brookings Institution.: 1-23.

Krupka, Douglas J. (2007). "Are big cities more segregated? Neighborhood Scale and the Measurement of Segregation." Urban Studies. Vol. 44 no.1 pp 187-197.

Massey, D. S. and M. L. Eggers (1990). "The Ecology of Inequality: Minorities and the Concentration of Poverty, 1970-1990." The American Journal of Sociology 95(5): 1153-1188.

Miller, V. P. and J. M. Quigley (1990). "Segregation by Racial and Demographic Group : Evidence from the San Francisco Bay Area." Urban Studies 27(1): 3-21.

Miyao, T. (1978). "Dynamic Instability of a mixed City in the Presence of Neighborhood Externalities." The American Economic Review 68(3): 454-463.

Muth, Richard F. (1969). Cities and Housing. Chicago: University of Chicago.

Rosenthal, S. S. (2008). "Old Homes, Externalities, and Poor Neighborhoods: A Model of Urban Decline and Renewal" forthcoming in The Journal of Urban Economics.

Schelling, T. C. (1969). "Models of Segregation." The American Economic Review 59(2): 488-493.

Schelling, T. C. (1971). "Dynamic Models of Segregation." Journal of Mathematical Sociology 1(2): 143-186.

Tiebout, Charles, "A Pure Theory of Local Expenditures," The Journal of Political Economy, LXIV (1956), 416-424. 
Appendix A: Table of Means.

\begin{tabular}{|c|c|c|c|}
\hline \multirow[b]{2}{*}{ Variable } & \multicolumn{3}{|c|}{ Year } \\
\hline & 2000 & 1990 & 1980 \\
\hline \multirow[t]{2}{*}{$\ln \sigma$} & 10.464 & 10.364 & 10.273 \\
\hline & 0.405 & 0.694 & 0.334 \\
\hline \multirow[t]{2}{*}{ CoVa } & 0.893 & 1.122 & 1.700 \\
\hline & 0.422 & 0.478 & 0.525 \\
\hline \multirow[t]{2}{*}{$\sigma$-resi } & -0.003 & -0.022 & -0.030 \\
\hline & 1.035 & 1.032 & 1.035 \\
\hline \multirow[t]{2}{*}{ CoVa-resi } & 0.003 & -0.020 & -0.016 \\
\hline & 1.011 & 0.777 & 0.703 \\
\hline \multirow[t]{2}{*}{ Income } & & 1.013 & 1.011 \\
\hline & & 0.454 & 0.352 \\
\hline \multirow[t]{2}{*}{ College } & 0.246 & 0.194 & 0.154 \\
\hline & 0.189 & 0.156 & 0.116 \\
\hline \multirow[t]{2}{*}{ Drop-Out } & 0.477 & 0.244 & 0.303 \\
\hline & 0.139 & 0.160 & 0.155 \\
\hline \multirow[t]{2}{*}{ Children } & 0.341 & 0.350 & 0.414 \\
\hline & 0.133 & 0.138 & 0.132 \\
\hline \multirow[t]{2}{*}{ White } & 0.720 & 0.787 & 0.826 \\
\hline & 0.289 & 0.281 & 0.253 \\
\hline \multirow[t]{2}{*}{ Wortkers } & 0.872 & 0.869 & 0.874 \\
\hline & 0.095 & 0.104 & 0.088 \\
\hline \multirow[t]{2}{*}{ Poverty } & 0.213 & & \\
\hline & 0.177 & & \\
\hline \multirow[t]{2}{*}{ Owners } & 0.654 & 0.605 & 0.656 \\
\hline & 0.264 & 0.254 & 0.225 \\
\hline \multirow[t]{2}{*}{ Stayers } & 0.515 & 0.496 & \\
\hline & 0.149 & 0.159 & \\
\hline \multirow[t]{2}{*}{ Value } & 11.692 & 11.349 & 10.800 \\
\hline & 0.644 & 0.697 & 0.521 \\
\hline \multirow[t]{2}{*}{ YearBuilt } & 1964.151 & 1961.504 & 1957.426 \\
\hline & 16.511 & 14.185 & 11.949 \\
\hline \multirow[t]{2}{*}{ Density } & 7.857 & 7.746 & 7.617 \\
\hline & 1.734 & 1.824 & 1.914 \\
\hline \multirow[t]{2}{*}{ Distance } & 2.623 & & \\
\hline & 0.710 & & \\
\hline \multirow[t]{2}{*}{ Vacancy } & & 0.074 & 0.064 \\
\hline & & 0.081 & 0.056 \\
\hline \multirow[t]{2}{*}{ Commute } & & 11.857 & 22.817 \\
\hline & & 4.173 & 6.519 \\
\hline \multirow[t]{2}{*}{ Age } & & & 31.285 \\
\hline & & & 6.230 \\
\hline
\end{tabular}

Note: Sample average and standard deviation. 
Table 1: OLS and First Differenced results

\begin{tabular}{|c|c|c|c|c|c|c|c|c|c|}
\hline \multirow{2}{*}{\multicolumn{2}{|c|}{ Panel }} & \multicolumn{8}{|c|}{ Model } \\
\hline & & 1 & II & III & IV & V & VI & VII & VIII \\
\hline \multirow{10}{*}{ A } & $\ln \sigma$ & 0.2741 & 0.1289 & 0.1313 & 0.0804 & -0.7736 & -0.8066 & -0.8080 & -0.7016 \\
\hline & st. Error & 0.0153 & 0.0086 & 0.0084 & 0.0061 & 0.0354 & 0.0372 & 0.0370 & 0.0581 \\
\hline & Income & & 0.4393 & 0.4222 & 0.0378 & & 0.2825 & 0.2957 & 0.2120 \\
\hline & st. Error & & 0.0051 & 0.0049 & 0.0035 & & 0.0155 & 0.0151 & 0.0216 \\
\hline & relsincome & & & 0.0396 & 0.0048 & & & 0.0330 & 0.0160 \\
\hline & st. Error & & & 0.0021 & 0.0015 & & & 0.0025 & 0.0014 \\
\hline & Control variables & None & None & None & 2000 & None & None & None & $1990-2000$ \\
\hline & Estimation Strategy & OLS & OLS & OLS & OLS & First Dif. & First Dif. & First Dif. & First Dif. \\
\hline & adj-rsq. & 0.2576 & 0.4542 & 0.4575 & 0.5929 & 0.5742 & 0.5959 & 0.5979 & 0.4397 \\
\hline & $N$ & 151337 & 151337 & 151337 & 146139 & 151099 & 151099 & 151099 & 144338 \\
\hline \multirow{10}{*}{ B } & Cova & 0.3875 & 0.2950 & 0.2863 & 0.1482 & -0.4149 & -0.4188 & -0.4146 & -0.4137 \\
\hline & st. Error & 0.0081 & 0.0085 & 0.0086 & 0.0065 & 0.0284 & 0.0320 & 0.0320 & 0.0368 \\
\hline & Income & & -0.2001 & -0.2269 & -0.0563 & & -0.0205 & -0.0071 & -0.0946 \\
\hline & st. Error & & 0.0043 & 0.0046 & 0.0045 & & 0.0182 & 0.0192 & 0.0240 \\
\hline & relsincome & & & 0.0555 & 0.0109 & & & 0.0290 & 0.0074 \\
\hline & st. Error & & & 0.0028 & 0.0019 & & & 0.0033 & 0.0038 \\
\hline & Control variables & None & None & None & 2000 & None & None & None & $1990-2000$ \\
\hline & Estimation Strategy & OLS & OLS & OLS & OLS & First Dif. & First Dif. & First Dif. & First Dif. \\
\hline & adj-rsq. & 0.2198 & 0.2554 & 0.2617 & 0.4006 & 0.2065 & 0.2066 & 0.2085 & 0.2682 \\
\hline & $\mathrm{N}$ & 151708 & 151708 & 151708 & 146318 & 151600 & 151600 & 151600 & 144603 \\
\hline
\end{tabular}

Note: standard errors are robust. Sample includes all Block Groups in Metropolitan areas with valid data. All regressions include Metropolitan area fixed effects. Dependant variable is specified measure of income mixing in 2000. 
Table 1 (cont): OLS and First Difference results.

\begin{tabular}{|c|c|c|c|c|c|c|c|c|c|}
\hline \multirow{2}{*}{\multicolumn{2}{|c|}{ Panel }} & \multicolumn{8}{|c|}{ Model } \\
\hline & & 1 & II & III & IV & $\mathrm{V}$ & VI & VII & VIII \\
\hline \multirow{10}{*}{ C } & $\sigma$-resi & 0.4187 & 0.4181 & 0.4220 & 0.2762 & -0.4363 & -0.4352 & -0.4315 & -0.4392 \\
\hline & st. Error & 0.0033 & 0.0033 & 0.0033 & 0.0034 & 0.0036 & 0.0036 & 0.0036 & 0.0033 \\
\hline & Income & & 0.1134 & 0.1466 & -0.0454 & & 0.0229 & -0.0096 & -0.1717 \\
\hline & st. Error & & 0.0067 & 0.0068 & 0.0133 & & 0.0138 & 0.0141 & 0.0138 \\
\hline & relsincome & & & -0.0823 & -0.1713 & & & -0.0939 & -0.1201 \\
\hline & st. Error & & & 0.0078 & 0.0067 & & & 0.0063 & 0.0054 \\
\hline & Control variables & None & None & None & 2000 & None & None & None & $1990-2000$ \\
\hline & Estimation Strategy & OLS & OLS & OLS & OLS & First Dif. & First Dif. & First Dif. & First Dif. \\
\hline & adj-rsq. & 0.2014 & 0.2039 & 0.2062 & 0.2910 & 0.1824 & 0.1824 & 0.1861 & 0.2107 \\
\hline & $\mathrm{N}$ & 151708 & 151708 & 151708 & 146318 & 151619 & 151619 & 151619 & 144610 \\
\hline \multirow{10}{*}{$\mathrm{D}$} & Cova-resi & 0.4666 & 0.4668 & 0.4426 & 0.2308 & -0.4695 & -0.4693 & -0.4583 & -0.4414 \\
\hline & st. Error & 0.0122 & 0.0123 & 0.0123 & 0.0095 & 0.0332 & 0.0333 & 0.0329 & 0.0371 \\
\hline & Income & & -0.0161 & -0.1282 & -0.0070 & & 0.0084 & 0.0554 & -0.0245 \\
\hline & st. Error & & 0.0070 & 0.0076 & 0.0086 & & 0.0095 & 0.0110 & 0.0144 \\
\hline & relsincome & & & 0.2794 & 0.1473 & & & 0.1188 & 0.0892 \\
\hline & st. Error & & & 0.0064 & 0.0045 & & & 0.0064 & 0.0065 \\
\hline & Control variables & None & None & None & 2000 & None & None & None & $1990-2000$ \\
\hline & Estimation Strategy & OLS & OLS & OLS & OLS & First Dif. & First Dif. & First Dif. & First Dif. \\
\hline & adj-rsq. & 0.1539 & 0.1539 & 0.1816 & 0.3063 & 0.1471 & 0.1471 & 0.1538 & 0.1738 \\
\hline & $\mathrm{N}$ & 151708 & 151708 & 151708 & 146318 & 151600 & 151600 & 151600 & 144603 \\
\hline
\end{tabular}

Note: standard errors are robust. Sample includes all Block Groups in Metropolitan areas with valid data. All regressions include Metropolitan area fixed effects. Dependant variable is specified measure of income mixing in 2000. 
Table 2: Instrumental Variables Results.

\begin{tabular}{|c|c|c|c|c|c|c|c|c|c|c|c|c|c|c|c|c|}
\hline Panel & & I & II & III & IV & V & VI & VII & VIII & IX & $x$ & XI & XII & XIII & XIV & $X V$ \\
\hline \multirow{10}{*}{ A } & $\ln \sigma$ & 0.7624 & 0.5732 & 0.5759 & 0.2871 & 0.9383 & 1.0218 & 1.0175 & 0.1463 & 0.5640 & 0.5551 & 0.5552 & 0.5464 & 0.6378 & 0.6372 & 0.6269 \\
\hline & st. Error & 0.0528 & 0.0923 & 0.0915 & 0.0794 & 0.0050 & 0.0200 & 0.0200 & 0.0215 & 0.0260 & 0.0264 & 0.0263 & 0.0273 & 0.0255 & 0.0255 & 0.0253 \\
\hline & Income & & 0.1894 & 0.1675 & -0.0196 & & -0.0624 & -0.0835 & 0.0214 & & 0.1163 & 0.1027 & -0.0825 & -0.0020 & -0.0077 & -0.0463 \\
\hline & st. Error & & 0.0519 & 0.0521 & 0.0225 & & 0.0139 & 0.0136 & 0.0067 & & 0.0129 & 0.0129 & 0.0120 & 0.0112 & 0.0108 & 0.0105 \\
\hline & relsInc. & & & 0.0515 & 0.0096 & & & 0.0590 & 0.0060 & & & 0.0340 & 0.0116 & & 0.0143 & 0.0002 \\
\hline & st. Error & & & 0.0055 & 0.0028 & & & 0.0091 & 0.0017 & & & 0.0051 & 0.0036 & & 0.0024 & 0.0022 \\
\hline & Controls & None & None & None & 2000 & None & None & None & 2000 & 80 & 80 & 80 & 80,2000 & 80,90 & 80,90 & All \\
\hline & Strategy & IV & IV & IV & IV & 2SLS & 2SLS & 2SLS & $2 S L S$ & IV & IV & IV & IV & IV & IV & IV \\
\hline & adj-rsq. & -0.1081 & 0.1921 & 0.1944 & 0.5584 & -0.2631 & -0.4303 & -0.4139 & 0.5941 & 0.3039 & 0.3179 & 0.3202 & 0.4436 & & 0.4380 & 0.4807 \\
\hline & $\mathrm{N}$ & 151099 & 151099 & 151099 & 145922 & 148478 & 148478 & 148478 & 144947 & 148403 & 148403 & 148403 & 144872 & 144680 & 144680 & 143381 \\
\hline \multirow{11}{*}{ B } & & & & & & & & & & & & & & & & \\
\hline & Cova & 0.7513 & 0.7869 & 0.7775 & 0.4783 & 0.8175 & 0.7459 & 0.7287 & 0.3513 & 0.5711 & 0.5621 & 0.5574 & 0.4376 & 0.5172 & 0.5140 & 0.4359 \\
\hline & st. Error & 0.0213 & 0.0365 & 0.0370 & 0.0528 & 0.0079 & 0.0087 & 0.0086 & 0.0198 & 0.0727 & 0.0657 & 0.0657 & 0.0624 & 0.0723 & 0.0722 & 0.0657 \\
\hline & Income & & 0.0423 & 0.0298 & 0.1432 & & 0.0229 & 0.0048 & 0.0684 & & 0.0555 & 0.0418 & 0.1550 & 0.1827 & 0.1719 & 0.1539 \\
\hline & st. Error & & 0.0174 & 0.0185 & 0.0309 & & 0.0034 & 0.0040 & 0.0123 & & 0.0371 & 0.0375 & 0.0390 & 0.0480 & 0.0481 & 0.0431 \\
\hline & relsinc. & & & 0.0195 & 0.0118 & & & 0.0240 & 0.0122 & & & 0.0268 & 0.0127 & & 0.0212 & 0.0109 \\
\hline & st. Error & & & 0.0034 & 0.0022 & & & 0.0031 & 0.0021 & & & 0.0029 & 0.0023 & & 0.0024 & 0.0021 \\
\hline & Controls & None & None & None & 2000 & None & None & None & 2000 & 80 & 80 & 80 & 80,2000 & 80,90 & 80,90 & All \\
\hline & Strategy & IV & IV & IV & IV & $2 S L S$ & 2SLS & 2SLS & $2 S L S$ & IV & IV & IV & IV & IV & IV & IV \\
\hline & adj-rsq. & 0.0578 & 0.0264 & 0.0360 & 0.3143 & -0.0089 & 0.0612 & 0.0768 & 0.3685 & 0.2019 & 0.2085 & 0.2125 & 0.3377 & 0.2524 & 0.2549 & 0.3453 \\
\hline & $\mathrm{N}$ & 151600 & 151600 & 151600 & 146242 & 148678 & 148678 & 148678 & 145021 & 148678 & 148678 & 148678 & 145021 & 144866 & 144866 & 143504 \\
\hline
\end{tabular}

Note: All standard errors are robust. All regressions include Metropolitan area fixed effects. Dependant variable is measure of income mixing in 2000 . IV columns instrument for 1990 income mixing with 1980 income mixing. 2SLS columns instrument with a battery of 1980 predictors of income mixing. In the row for controls, "2000" signifies a battery of year 2000 predictors of income mixing, "80" and "90" signify batteries of income mixing predictors for 1980 and 1990 respectively. 
Table 2 (cont): Instrumental Variables Results.

\begin{tabular}{|c|c|c|c|c|c|c|c|c|c|c|c|c|c|c|c|c|}
\hline Panel & & 1 & II & III & IV & V & VI & VII & VIII & IX & $x$ & XI & XII & XIII & XIV & $X V$ \\
\hline \multirow{10}{*}{$c$} & $\sigma$-resi & 0.7744 & 0.7615 & 0.7721 & 0.6160 & 0.8672 & 0.8070 & 0.8296 & 0.4751 & 0.7086 & 0.6976 & 0.7030 & 0.6827 & 0.6902 & 0.6969 & 0.6951 \\
\hline & st. Error & 0.0073 & 0.0072 & 0.0073 & 0.0111 & 0.0071 & 0.0066 & 0.0067 & 0.0190 & 0.0119 & 0.0114 & 0.0114 & 0.0119 & 0.0127 & 0.0127 & 0.0124 \\
\hline & Income & & 0.1005 & 0.1527 & 0.2352 & & 0.0921 & 0.1491 & 0.1163 & & 0.2391 & 0.3057 & 0.3796 & 0.4078 & 0.4813 & 0.4817 \\
\hline & st. Error & & 0.0072 & 0.0071 & 0.0164 & & 0.0071 & 0.0069 & 0.0211 & & 0.0139 & 0.0138 & 0.0188 & 0.0247 & 0.0245 & 0.0237 \\
\hline & $r e l \Delta I n c$. & & & -0.1300 & -0.1787 & & & -0.1438 & -0.1765 & & & -0.1546 & -0.1873 & & -0.1614 & -0.1954 \\
\hline & st. Error & & & 0.0084 & 0.0071 & & & 0.0082 & 0.0069 & & & 0.0077 & 0.0073 & & 0.0072 & 0.0070 \\
\hline & Controls & None & None & None & 2000 & None & None & None & 2000 & 80 & 80 & 80 & 80,2000 & 80,90 & 80,90 & All \\
\hline & Strategy & IV & IV & IV & IV & 2SLS & $2 S L S$ & $2 S L S$ & 2SLS & IV & IV & IV & IV & IV & IV & IV \\
\hline & adj-rsq. & 0.0822 & 0.0927 & 0.0914 & 0.2073 & 0.0187 & 0.0674 & 0.0574 & 0.2648 & 0.1349 & 0.1450 & 0.1495 & 0.1790 & 0.1492 & 0.1535 & 0.1789 \\
\hline & $\mathrm{N}$ & 151619 & 151619 & 151619 & 146250 & 148678 & 148678 & 148678 & 145021 & 148678 & 148678 & 148678 & 145021 & 144866 & 144866 & 143504 \\
\hline \multirow{10}{*}{ D } & Cova-resi & 1.0158 & 1.0238 & 0.9785 & 0.6176 & 1.1649 & 1.1546 & 1.0840 & 0.6391 & 0.8516 & 0.8426 & 0.8232 & 0.6596 & 0.7688 & 0.7529 & 0.6496 \\
\hline & st. Error & 0.0455 & 0.0467 & 0.0462 & 0.0678 & 0.0114 & 0.0119 & 0.0116 & 0.0292 & 0.0977 & 0.0958 & 0.0953 & 0.0965 & 0.1067 & 0.1060 & 0.1007 \\
\hline & Income & & -0.0403 & -0.1215 & 0.0700 & & -0.0404 & -0.1145 & 0.0865 & & 0.1156 & 0.0297 & 0.1427 & 0.2833 & 0.2006 & 0.1839 \\
\hline & st. Error & & 0.0081 & 0.0082 & 0.0143 & & 0.0081 & 0.0086 & 0.0113 & & 0.0159 & 0.0169 & 0.0260 & 0.0387 & 0.0386 & 0.0349 \\
\hline & relsinc. & & & 0.2061 & 0.1524 & & & 0.1922 & 0.1535 & & & 0.2015 & 0.1517 & & 0.1886 & 0.1451 \\
\hline & st. Error & & & 0.0080 & 0.0054 & & & 0.0074 & 0.0052 & & & 0.0072 & 0.0058 & & 0.0056 & 0.0054 \\
\hline & Controls & None & None & None & 2000 & None & None & None & 2000 & 80 & 80 & 80 & 80,2000 & 80,90 & 80,90 & All \\
\hline & Strategy & IV & IV & IV & IV & 2SLS & $2 S L S$ & 2SLS & $2 S L S$ & IV & IV & IV & IV & IV & IV & IV \\
\hline & adj-rsq. & -0.0170 & -0.0217 & 0.0210 & 0.2360 & -0.1217 & -0.1134 & -0.0482 & 0.2296 & 0.0848 & 0.0901 & 0.1129 & 0.2230 & 0.1426 & 0.1618 & 0.2362 \\
\hline & $\mathrm{N}$ & 151600 & 151600 & 151600 & 146242 & 148678 & 148678 & 148678 & 145021 & 148678 & 148678 & 148678 & 145021 & 144866 & 144866 & 143504 \\
\hline
\end{tabular}

Note: All standard errors are robust. All regressions include Metropolitan area fixed effects. Dependant variable is measure of income mixing in 2000 . IV columns instrument for 1990 income mixing with 1980 income mixing. 2SLS columns instrument with a battery of 1980 predictors of income mixing. In the row for controls, "2000" signifies a battery of year 2000 predictors of income mixing, " 80 " and "90" signify batteries of income mixing predictors for 1980 and 1990 respectively. 
Table 3: Difference equation results.

\begin{tabular}{|c|c|c|c|c|c|c|c|c|c|c|c|}
\hline \multirow{2}{*}{ Panel } & & \multicolumn{10}{|c|}{ Model } \\
\hline & & I & II & III & IV & V & VI & VII & VIII & IX & $x$ \\
\hline \multirow{10}{*}{ A } & $\ln \sigma$ & -0.0867 & -0.5330 & -0.5673 & -0.5435 & -0.1698 & -0.2051 & -0.6776 & 0.2446 & 0.2461 & 0.2336 \\
\hline & st. Error & 0.0235 & 0.0286 & 0.0280 & 0.0342 & 0.0635 & 0.0640 & 0.0385 & 0.0306 & 0.0308 & 0.0292 \\
\hline & Income & & 0.1729 & 0.1955 & 0.1526 & 0.0000 & 0.0096 & 0.0520 & -0.0966 & -0.1035 & -0.1286 \\
\hline & st. Error & & 0.0132 & 0.0131 & 0.0129 & 0.0183 & 0.0196 & 0.0095 & 0.0179 & 0.0192 & 0.0193 \\
\hline & relsIncome & & & 0.0245 & 0.0096 & & 0.0045 & 0.0059 & & -0.0075 & -0.0156 \\
\hline & st. Error & & & 0.0028 & 0.0016 & & 0.0027 & 0.0015 & & 0.0032 & 0.0032 \\
\hline & Controls & None & None & None & $1990-2000$ & $1980-1990$ & $1980-1990$ & $\begin{array}{l}1980-1990 \\
1990-2000\end{array}$ & $\begin{array}{c}1980 \\
1980-1990\end{array}$ & $\begin{array}{c}1980 \\
1980-1990\end{array}$ & $\begin{array}{c}1980 \\
1980-1990 \\
1990-2000\end{array}$ \\
\hline & Strategy & $2 S L S$ & $2 S L S$ & $2 S L S$ & $2 S L S$ & $2 S L S$ & $2 S L S$ & $2 S L S$ & IV & IV & IV \\
\hline & adj-rsq. & 0.1262 & 0.5278 & 0.5463 & 0.4162 & 0.1771 & 0.2050 & 0.4606 & 0.5941 & -0.2688 & -0.2147 \\
\hline & $\mathrm{N}$ & 148403 & 148403 & 148403 & 145922 & 148478 & 148478 & 148478 & 144947 & 148403 & 148403 \\
\hline \multirow{10}{*}{ B } & Cova & 0.2945 & 0.3311 & 0.3118 & 0.3055 & 0.4515 & 0.4394 & 0.2951 & 0.1333 & 0.1317 & 0.1270 \\
\hline & st. Error & 0.0208 & 0.0243 & 0.0234 & 0.0266 & 0.0620 & 0.0603 & 0.0528 & 0.0435 & 0.0438 & 0.0431 \\
\hline & Income & & 0.4579 & 0.4747 & 0.4370 & 0.7869 & 0.8511 & 0.7093 & 0.5996 & 0.6649 & 0.6188 \\
\hline & st. Error & & 0.0162 & 0.0163 & 0.0177 & 0.0444 & 0.0464 & 0.0417 & 0.0333 & 0.0355 & 0.0361 \\
\hline & relsincome & & & 0.0787 & 0.0651 & & 0.0907 & 0.0772 & & 0.0749 & 0.0681 \\
\hline & st. Error & & & 0.0035 & 0.0033 & & 0.0050 & 0.0044 & & 0.0035 & 0.0034 \\
\hline & Controls & None & None & None & $1990-2000$ & $1980-1990$ & $1980-1990$ & $\begin{array}{l}1980-1990 \\
1990-2000\end{array}$ & $\begin{array}{c}1980 \\
1980-1990\end{array}$ & $\begin{array}{c}1980 \\
1980-1990\end{array}$ & $\begin{array}{c}1980 \\
1980-1990 \\
1990-2000\end{array}$ \\
\hline & Strategy & $2 S L S$ & $2 S L S$ & $2 S L S$ & $2 S L S$ & $2 S L S$ & $2 S L S$ & $2 S L S$ & IV & IV & IV \\
\hline & adj-rsq. & -0.3718 & -0.3592 & -0.3170 & -0.2412 & -0.4879 & -0.4494 & -0.1928 & 0.3685 & -0.0341 & 0.0111 \\
\hline & $N$ & 148678 & 148678 & 148678 & 146242 & 148678 & 148678 & 148678 & 145021 & 148678 & 148678 \\
\hline
\end{tabular}

Note: All standard errors are robust. Dependant variable is specified measure of income mixing. All regressions include metropolitan fixed effects. 2SLS columns use a battery of 1980 predictors of 1980 income mixing as instruments. IV columns use 1980 measure of income mixing. Controls include changes in levels of control variables for 1990-2000, and for 1980-1990 (as indicated) as well as the levels (where indicated) of these predictors in 1980. 
Table 3 (cont.): Difference equation results.

\begin{tabular}{|c|c|c|c|c|c|c|c|c|c|c|c|}
\hline \multirow{2}{*}{ Panel } & & \multicolumn{10}{|c|}{ Model } \\
\hline & & I & II & III & IV & $\mathrm{V}$ & VI & VII & VIII & IX & $x$ \\
\hline \multirow{10}{*}{ C } & $\sigma$-resi & 0.2404 & 0.3190 & 0.3329 & 0.3394 & 0.2040 & 0.2030 & 0.1570 & 0.1376 & 0.1413 & 0.1386 \\
\hline & st. Error & 0.0177 & 0.0211 & 0.0210 & 0.0207 & 0.0209 & 0.0204 & 0.0230 & 0.0069 & 0.0069 & 0.0065 \\
\hline & Income & & 0.5148 & 0.4650 & 0.3769 & 0.9475 & 0.8393 & 0.6969 & 0.9137 & 0.8100 & 0.6958 \\
\hline & st. Error & & 0.0222 & 0.0220 & 0.0225 & 0.0342 & 0.0336 & 0.0365 & 0.0244 & 0.0253 & 0.0256 \\
\hline & relsIncome & & & -0.1600 & -0.1814 & & -0.1319 & -0.1456 & & -0.1221 & -0.1435 \\
\hline & st. Error & & & 0.0069 & 0.0069 & & 0.0064 & 0.0064 & & 0.0062 & 0.0063 \\
\hline & Controls & None & None & None & $1990-2000$ & $1980-1990$ & $1980-1990$ & $\begin{array}{l}1980-1990 \\
1990-2000\end{array}$ & $\begin{array}{c}1980 \\
1980-1990\end{array}$ & $\begin{array}{c}1980 \\
1980-1990\end{array}$ & $\begin{array}{c}1980 \\
1980-1990 \\
1990-2000\end{array}$ \\
\hline & Strategy & $2 S L S$ & $2 S L S$ & $2 S L S$ & $2 S L S$ & $2 S L S$ & $2 S L S$ & $2 S L S$ & IV & IV & IV \\
\hline & adj-rsq. & -0.2450 & -0.3329 & -0.3414 & -0.3251 & -0.1631 & -0.1552 & -0.0889 & 0.2648 & -0.0859 & -0.0659 \\
\hline & $\mathrm{N}$ & 148678 & 148678 & 148678 & 146250 & 148678 & 148678 & 148678 & 145021 & 148678 & 148678 \\
\hline \multirow{10}{*}{$\mathrm{D}$} & CoVa-resi & -0.0301 & 0.0206 & -0.0683 & 0.0577 & 0.0318 & 0.0163 & 0.1800 & 0.0708 & 0.0682 & 0.0696 \\
\hline & st. Error & 0.0306 & 0.0368 & 0.0352 & 0.0464 & 0.0337 & 0.0333 & 0.0665 & 0.0434 & 0.0438 & 0.0440 \\
\hline & Income & & 0.1338 & 0.1729 & 0.1344 & 0.3508 & 0.4971 & 0.4827 & 0.3924 & 0.5744 & 0.4311 \\
\hline & st. Error & & 0.0142 & 0.0151 & 0.0151 & 0.0209 & 0.0233 & 0.0358 & 0.0270 & 0.0305 & 0.0316 \\
\hline & relsincome & & & 0.1666 & 0.1499 & & 0.1891 & 0.1844 & & 0.2065 & 0.1764 \\
\hline & st. Error & & & 0.0062 & 0.0062 & & 0.0056 & 0.0087 & & 0.0062 & 0.0063 \\
\hline & Controls & None & None & None & $1990-2000$ & $1980-1990$ & $1980-1990$ & $\begin{array}{l}1980-1990 \\
1990-2000\end{array}$ & $\begin{array}{c}1980 \\
1980-1990\end{array}$ & $\begin{array}{c}1980 \\
1980-1990\end{array}$ & $\begin{array}{c}1980 \\
1980-1990 \\
1990-2000\end{array}$ \\
\hline & Strategy & $2 S L S$ & $2 S L S$ & $2 S L S$ & $2 S L S$ & $2 S L S$ & $2 S L S$ & $2 S L S$ & IV & IV & IV \\
\hline & adj-rsq. & 0.0227 & -0.0064 & 0.0578 & 0.0096 & -0.0069 & 0.0209 & -0.0712 & 0.2296 & -0.0039 & 0.0177 \\
\hline & $N$ & 148678 & 148678 & 148678 & 146242 & 148678 & 148678 & 148678 & 145021 & 148678 & 148678 \\
\hline
\end{tabular}

Note: All standard errors are robust. Dependant variable is specified measure of income mixing. All regressions include metropolitan fixed effects. 2SLS columns use a battery of 1980 predictors of 1980 income mixing as instruments. IV columns use 1980 measure of income mixing. Controls include changes in levels of control variables for 1990-2000, and for 1980-1990 (as indicated) as well as the levels (where indicated) of these predictors in 1980. 